\title{
Uncertainty Shocks and Unemployment Dynamics in U.S. Recessions*
}

\author{
Giovanni Caggiano \\ University of Padova
}

\author{
Efrem Castelnuovo \\ University of Melbourne \\ University of Padova \\ Bank of Finland
}

\author{
Nicolas Groshenny \\ University of Adelaide
}

March 2015

\begin{abstract}
What are the effects of uncertainty shocks on unemployment dynamics? We answer this question by estimating non-linear (Smooth-Transition) VARs with post-WWII U.S. data. The relevance of uncertainty shocks is found to be much larger than that predicted by standard linear VARs in terms of i) magnitude of the reaction of the unemployment rate to such shocks, and ii) contribution to the variance of the prediction errors of unemployment at business cycle frequencies. The ability of different classes of DSGE models to replicate our results is discussed.
\end{abstract}

Keywords: Uncertainty shocks, Unemployment Dynamics, Smooth Transition Vector-AutoRegressions, Recessions.

JEL codes: C32, E32, E52.

*A shorter version of this paper has been published as: Caggiano, G., E. Castelnuovo, and N. Groshenny, 2014, Uncertainty Shocks and Unemployment Dynamics in U.S. Recessions, Journal of Monetary Economics, 67, 78-92. We thank Giorgio Primiceri (Associate Editor) and an anonymous referee for their very useful comments. We also thank Guido Ascari, Christian Bayer, Sandra Eickmeier, Martin Ellison, Steffen Elstner, Ana Galvão, Kyle Jurado, Riccardo Lucchetti, Bartosz Maćkowiak, Sophocles Mavroeidis, Serena Ng, Irina Panovska, Evi Pappa, Raffaella Santolini, Konstantinos Theodoridis and participants to seminars held at the Universities of Helsinki, Oxford, Politecnica delle Marche, the Bank of Finland, and presentations held at the XXI International Conference on Money, Banking and Finance (Luiss, Rome), the 21st Symposium of the Society for Non-linear Dynamics and Econometrics (Bicocca University, Milan), the 8th BMRC-QASS Conference on Macro and Financial Economics (Brunel University), and the Padova Macroeconomics Meetings 2013 for their useful feedbacks. Gabriela Nodari provided excellent research assistance. Part of this research was conducted while the first author was visiting Columbia University, whose kind hospitality is gratefully acknowledged. The opinions expressed in this paper do not necessarily reflect those of the Bank of Finland. All errors are ours. Corresponding author: Giovanni Caggiano, University of Padova, Department of Economics and Management, via del Santo 33, 35123 Padova (Italy). Phone: +39 049 827 3843. Email address: giovanni.caggiano@unipd.it . 


\section{Introduction}

The U.S. unemployment rate has experienced a substantial upswing during the 20072009 economic crisis, moving from $4.4 \%$ in May 2007 to $10.1 \%$ in October 2009. Since then, the recovery of the labor market has been marked but not full. In January 2013, unemployment was assessed to be some $2 \%$ larger than its longer-run value by most FOMC participants (Yellen, 2013). Clearly, the identification of the drivers behind the evolution of the U.S. unemployment rate is of primary importance to policymakers. Increasing attention has recently been paid to the role played by uncertainty. As stated by John Williams, ${ }^{1}$ "There's pretty strong evidence that the rise in uncertainty is a significant factor holding back the pace of recovery now. [...] research shows that heightened uncertainty slows economic growth, raises unemployment, and reduces inflationary pressures. [...] There's no question that slow growth, high unemployment, and significant uncertainty are challenges for monetary policy."

This paper investigates the impact of uncertainty shocks on unemployment during U.S. post-WWII recessionary episodes. Since the seminal contribution by Bloom (2009), a large number of papers have been concerned with the role of uncertainty at a macroeconomic level (for a comprehensive survey, see Bloom, Fernández-Villaverde, and Schneider (2013)). Part of the literature has studied the impact of uncertainty shocks with Dynamic Stochastic General Equilibrium models. ${ }^{2}$ A related empirical literature has dealt with the identification of uncertainty shocks by employing linear VAR models. Recent contributions include Bloom (2009), Alexopoulos and Cohen (2009), Bachmann, Elstner, and Sims (2013), Mumtaz and Theodoridis (2012), Baker, Bloom, and Davis

\footnotetext{
${ }^{1}$ John Williams, President and Chief Executive Officer of the Federal Reserve Bank of San Francisco, FRBSF Economic Letter, January 21, 2013.

${ }^{2}$ A non-exhaustive list of studies includes Fernández-Villaverde, Guerrón-Quintana, Rubio-Ramírez, and Uribe (2011), Benigno, Benigno, and Nisticò (2012), Mumtaz and Theodoridis (2012), Bianchi and Melosi (2013), Bachmann and Bayer (2013), Bachmann, Elstner, and Sims (2013), Basu and Bundick (2014), Leduc and Liu (2013), Christiano, Motto, and Rostagno (2014), and Bloom, Floetotto, Jaimovich, Saporta-Eksten, and Terry (2014).
} 
(2013), Gilchrist, Sim, and Zakrajsek (2013), Leduc and Liu (2013), Colombo (2013), Mumtaz and Surico (2013), Nodari (2014). Linear VAR frameworks are standard tools in the empirical macroeconomic literature. However, the U.S. unemployment rate has been found to be characterized by asymmetric dynamics across different phases of the business cycle (Koop and Potter, 1999; van Dijk, Teräsvirta, and Franses, 2002; Morley and Piger, 2012; Morley, Piger, and Tien, 2013), a stylized fact which naturally leads to the adoption of non-linear frameworks. Moreover, uncertainty is typically high during recessions, when unemployment also tends to increase abruptly (Jurado, Ludvigson, and $\mathrm{Ng}, 2013)$. For these reasons, recessionary episodes are very likely to be quite informative phases for the identification of the effects of uncertainty shocks on unemployment.

We isolate the impact of uncertainty shocks during recessions by modeling U.S. quarterly data on uncertainty, unemployment, and other standard macroeconomic variables with Smooth Transition Vector AutoRegressions (STVARs). ${ }^{3}$ The STVAR set up conveniently allows us to isolate recessionary episodes while retaining enough information to estimate a richly parametrized VAR framework. To understand to what extent non-linearities are important for uncovering the effects of uncertainty shocks, the predictions of the non-linear STVAR models conditional on recessions are then contrasted with those produced with standard linear VARs.

Our main results are the following. First, the impact of uncertainty shocks on unem-

\footnotetext{
${ }^{3}$ Section 2 develops this argument further. For a paper dealing with instabilities in the macroeconomic effects of uncertainty shocks via a rolling-window VAR approach, see Beetsma and Giuliodori (2012). An investigation dealing with instabilities via a time-varying VAR approach is proposed by Benati (2013). A related approach is that by Enders and Jones (2013), who estimate Logistic Smooth Transition Autoregressive Models for a number of macroeconomic indicators. They isolate different effects of uncertainty shocks in presence of "high" vs. "low" uncertainty. Differently, this paper focuses on the effects of uncertainty shocks during recessions (i.e., phases of "low" economic growth) and contrast such effects to what is typically found with standard linear VARs. In doing so, we employ a multivariate framework to model the systematic interaction among policy-relevant macroeconomic indicators such as inflation, unemployment, and a short-term interest rate. This enables us to control for spurious evidence of non-linearity possibly arising when omitting to model systematic interactions among structurally related variables.
} 
ployment is shown to be substantially underestimated if one does not take into account that they typically occur in recessions. A linear VAR model returns estimates suggesting that a one standard deviation increase in the VIX, our proxy for uncertainty, may induce a reaction of the unemployment rate of about 0.17 percentage points four quarters after the shock, and of about 0.14 percentage points eight quarters after such shock. The non-linear VAR reveals that the same shock, when hitting the economy during a recession, is estimated to induce a much larger (and statistically different) increase in unemployment of 0.36 percentage points four quarters after the shock, and 0.41 two years after the shock. Evidence of non-linear dynamics is also found for the policy rate and inflation. The asymmetry result holds not only for unemployment, but also for a number of alternative real activity indicators, including hours, output, investment, durable and nondurable consumption. Second, consistently with the previous findings, the contribution of uncertainty shocks to the forecast error variance decomposition of the unemployment rate at business cycle frequencies is estimated to be (at least) three times larger in a non-linear VAR model. Interestingly, such shocks turn out to be more powerful than monetary policy shocks as a driver of the U.S. unemployment rate. A battery of checks, dealing with a different data-frequency, a number of additional variables in our VARs, different identification schemes, different empirical proxies for uncertainty, and a shorter sample omitting the zero-lower bound, confirm the robustness of our results. Wrapping up, the non-linear VAR analysis suggests that uncertainty shocks may be markedly more costly than previously estimated via linear frameworks. ${ }^{4}$

\footnotetext{
${ }^{4}$ In principle, it is possible that the countercyclical evolution of uncertainty is endogenous and due to movements in the business cycle, more than a cause of such movements. Bachmann and Moscarini (2012) propose a model in which strategic price experimentation during bad economic times (due to first moment shocks) leads to a higher dispersion of firms' profits. Baker and Bloom (2013) use natural disasters and events like terrorist attacks and unexpected political shocks to isolate exogenous increases in uncertainty in a panel of countries. They find the contribution of second moment shocks to explain at least half of the variation in real GDP growth.
} 
Overall, our findings corroborate those presented in previous contributions on the asymmetries characterizing the evolution of the unemployment rate over the business cycle. Koop and Potter (1999) perform an extensive model comparison involving linear and non-linear models for the U.S. unemployment rate. They find clear evidence in favor of a non-linear threshold autoregressive model featuring two distinct regimes. In their survey on STVAR models, van Dijk, Teräsvirta, and Franses (2002) provide further evidence in favor of asymmetric dynamics of the U.S. unemployment rate across different regimes. Morley and Piger (2012) construct an indicator of the U.S. business cycle by averaging a variety of competing linear and non-linear statistical frameworks. The resulting indicator clearly points to variations in the cycle larger during recessions than in expansionary periods. Interestingly, their measure displays an asymmetric shape and it is shown to be closely related to the unemployment rate. Importantly, Morley, Piger, and Tien (2013) show that the relevance of non-linearities for modeling an indicator of the business cycle survives also when considering a multivariate approach.

Our results are also of interest from a modeling standpoint. Gilchrist and Williams (2005) show that, in a standard real business cycle (RBC) set up featuring a Walrasian labor market, uncertainty shocks are expansionary because they negatively affect households' wealth, therefore increasing households' marginal utility of consumption and labor supply. Leduc and Liu (2013) show that this conclusion is overturned when some real frictions are added to the framework. In particular, in a model with search frictions in the labor market, positive uncertainty shocks negatively affect potential output. This occurs because firms pause hiring new workers when uncertainty hits the economy due to the lower expected value of a filled vacancy. As a consequence, firms post a lower number of vacancies, so inducing a drop in the job finding rate and an increase in the unemployment rate. In presence of sticky prices in the intermediate sector, this conclusion is reinforced. Facing an uncertainty shock, aggregate demand drops, so leading 
firms to lower their relative prices. Such decline reduces even further the value of a vacancy, therefore raising unemployment even more. Leduc and Liu (2013) notice that, in a sticky price framework, an uncertainty shock lowers inflation as well, and therefore can be interpreted as a demand shock. A similar conclusion is reached by Basu and Bundick (2014), who show that sticky prices are important to generate a contraction in output and its components after an exogenous increase in uncertainty. Our empirical findings support the conclusions by these two latter papers, as we show that uncertainty shocks are demand shocks. Hence our results suggest that labor market frictions and sticky prices are relevant frictions to interpret the macroeconomic effects of uncertainty shocks during recessions.

The structure of the paper is the following. Section 2 offers statistical support in favor of a non-linear relationship between unemployment and uncertainty, presents the Smooth Transition VAR model employed in our analysis, and explains the reasons behind our choice of focusing on recessions. Section 3 presents our results, whose robustness is documented in Section 4. Section 5 provides further evidence on the importance to employ non-linear models when dealing with uncertainty shocks. Section 6 concludes.

\section{Empirical investigation}

The aim of this Section is twofold. First, our Smooth-Transition VAR model is presented. Second, the reasons behind our focus on U.S. recessions are discussed.

Data and methodology. As anticipated in the Introduction, the macroeconomic effects of uncertainty shocks during post-WWII U.S. recessions are identified by modeling some selected U.S. macroeconomic series with a Smooth-Transition VAR framework. Granger and Teräsvirta (1993) offer a presentation on STVARs and discuss some issues related to their estimation. A survey on recent developments in this area is proposed 
by van Dijk, Teräsvirta, and Franses (2002).

Formally, our STVAR model reads as follows:

$$
\begin{aligned}
\boldsymbol{X}_{t} & =F\left(z_{t-1}\right) \boldsymbol{\Pi}_{R}(L) \boldsymbol{X}_{t}+\left(1-F\left(z_{t-1}\right)\right) \boldsymbol{\Pi}_{N R}(L) \boldsymbol{X}_{t}+\boldsymbol{\varepsilon}_{t}, \\
\boldsymbol{\varepsilon}_{t} & \sim N\left(0, \boldsymbol{\Omega}_{t}\right), \\
\boldsymbol{\Omega}_{t} & =F\left(z_{t-1}\right) \boldsymbol{\Omega}_{R}+\left(1-F\left(z_{t-1}\right)\right) \boldsymbol{\Omega}_{N R}, \\
F\left(z_{t}\right) & =\exp \left(-\gamma z_{t}\right) /\left(1+\exp \left(-\gamma z_{t}\right)\right), \gamma>0, z_{t} \sim N(0,1) .
\end{aligned}
$$

where $\boldsymbol{X}_{t}$ is a set of endogenous variables which we aim to model, $F\left(z_{t-1}\right)$ is a logistic transition function which captures the probability of being in a recession and whose smoothness parameter is $\gamma, z_{t}$ is a transition indicator, $\boldsymbol{\Pi}_{R}$ and $\boldsymbol{\Pi}_{N R}$ are the VAR coefficients capturing the dynamics of the system during recessions and non-recessionary phases (respectively), $\varepsilon_{t}$ is the vector of reduced-form residuals having zero-mean and whose time-varying, state-contingent variance-covariance matrix is $\boldsymbol{\Omega}_{t}$, and $\boldsymbol{\Omega}_{R}$ and $\Omega_{N R}$ are covariance matrices of the reduced-form residuals computed during recessions and non-recessions, respectively.

In short, this model assumes that our endogenous variables can be described as a linear combination of two linear VARs, i.e., one suited to describe the state of the economy during recessions and the other to be interpreted as a "catch all" vector modeling the remaining phase(s). Conditional on the standardized transition variable $z_{t}$, the logistic function $F\left(z_{t}\right)$ indicates the probability of being in a recessionary phase. The transition from a regime to another is regulated by the smoothness parameter $\gamma$. Large values of this parameter imply abrupt switches from a regime to another. Viceversa, moderate values of $\gamma$ enable the economic system to spend some time in each regime before switching to the alternative one. Importantly, the STVAR model allows for nonlinear effects as for both the contemporaneous relationships and the dynamics of our 
economic system.

Our baseline analysis hinges upon the vector $\boldsymbol{X}_{t}=\left[v i x_{t}, \pi_{t}, u_{t}, R_{t}\right]^{\prime}$, where vix stands for the VIX index, our proxy for uncertainty, $\pi_{t}$ stands for inflation, $u_{t}$ is the unemployment rate, $R_{t}$ is a policy rate. The Chicago Board Options Exchange Market Volatility Index (the VIX index) measures the implied volatility of the S\&P500 index options. This index, often referred to as "fear index", represents a measure of market expectations of stock market volatility at time $t$ over the next 30-day period. Before 1986 this index is unavailable. Following Bloom (2009), pre-1986 monthly returns volatilities are computed by employing the monthly standard deviation of the daily S\&P500 index normalized to the same mean and variance as the VIX index from 1986 onward. Inflation is computed as the annualized quarter-on-quarter percentage growth rate of the implicit GDP deflator. Unemployment is the monthly civilian unemployment rate. The policy rate is the federal funds rate. Quarterly observations of monthly data are constructed via quarterly averaging. The sample spans the 1962Q3-2012Q3 period, 1962Q3 being the first available quarter as for the uncertainty index. The source of our data is the FRED database on the Federal Reserve Bank of St. Louis' website.

The presence of non-linearities in the unemployment-uncertainty relationship is verified by running two tests. The first is based on a regression of unemployment rate on its own lags, uncertainty, and interaction terms between these two variables as regressors. As shown by Luukkonen, Saikkonen, and Teräsvirta (1988), the assumption of linearity is rejected if the coefficients of the interaction terms are jointly different from zero. To detect non-linear dynamics at a multivariate level, the test proposed by Teräsvirta and Yang (2013) is then performed. Their framework is particularly suited for our analysis since it amounts to test the null hypothesis of linearity versus a specified non-linear alternative, that of a (Logistic) Smooth Transition Vector AutoRegression with a single transition variable. In performing this multivariate test, we consider our vector of 
endogenous variables $\boldsymbol{X}_{t}$. Both tests suggest a clear rejection of the null hypothesis of linearity. ${ }^{5}$

The identification of exogenous variations of the uncertainty index is achieved via the widely adopted Cholesky-assumption. Given the ordering of the variables in $\boldsymbol{X}_{t}$, this implies that on-impact macroeconomic effects by our identified uncertainty shocks are allowed. While being a common assumption in the literature, it must be noted that demand and supply shocks influencing the equilibrium values of our macroeconomic indicators may also influence uncertainty within a quarter. Hence, no recursive ordering is probably right in this context. Moreover, ordering the VIX first in our vector attributes all the one-step-ahead forecast error in the VIX to uncertainty shocks. Consequently, our results should be interpreted as providing an upper bound on the effects of uncertainty shocks. ${ }^{6}$ Importantly, our results are robust to the employment of monthly data, which make the recursive identifying restriction more plausible (see Caggiano, Castelnuovo, and Groshenny, 2013).

A key role is played by the transition variable $z_{t}$. Following Auerbach and Gorodnichenko (2012), Bachmann and Sims (2012), and Berger and Vavra (2014), a standardized moving average involving seven realizations of the quarter-on-quarter real GDP growth rate is employed. The transition variable $z_{t}$ is standardized to render our calibration of the slope parameter $\gamma$ comparable to the ones employed in the literature. Auerbach and Gorodnichenko (2012) suggest to fix $\gamma$ to ease the estimation

\footnotetext{
${ }^{5}$ Technical details on these tests and their implementation, as well as further results not documented in this version of the paper, are reported in Caggiano, Castelnuovo, and Groshenny (2013).

${ }^{6}$ One of our robustness checks (presented in the next Section) deals with a different ordering of our variables with uncertainty ordered last. The estimates on the macroeconomic effects of uncertainty shocks in recessions turn out to be robust to this alternative ordering. In our VAR, uncertainty is captured by the VIX, which is a "second moment" by construction. Differently, the evolution of the second moments of other structural shocks in our vector is left unmodeled. However, our VAR features a time-varying covariance matrix of its residuals. Most likely, this captures the bulk of the volatility of the structural shocks other than the uncertainty shock. Hence, while in principle our "uncertainty shock" might pick up some unmodeled volatility of the remaining structural shocks, this case is likely to be negligible from an empirical standpoint.
} 
of the remaining parameters of highly non-linear STVARs like ours. The smoothness parameter $\gamma$ is calibrated by referring to the duration of recessions in the U.S. according to the NBER business cycle dates (17 percent of the time in our sample according to the dating proposed by the NBER). Then, "recessions" are defined as periods in which $F\left(z_{t}\right) \geqslant 0.83$, and $\gamma$ is calibrated so that $\operatorname{Pr}\left(F\left(z_{t}\right) \geqslant 0.83\right) \approx 0.17$. This metric implies a calibration $\gamma=1.75$, which is quite close to the 1.5 value employed by Auerbach and Gorodnichenko (2012), Bachmann and Sims (2012), and Berger and Vavra (2014). ${ }^{7}$

The transition function $F\left(z_{t}\right)$ is shown in Figure 1. Clearly, high realizations of $F\left(z_{t}\right)$ tend to be associated with NBER recessions. Notice that the a priori choice of a transition function provides us with information that we would otherwise need to recover from the data by estimating a latent factor dictating the switch from a state to another, as it occurs when Markov-Switching VAR frameworks are taken to the data.

Our (linear/non-linear) VAR features three lags. This choice is justified by the Akaike criterion when applied to a linear model estimated on the full-sample 1962Q32012Q3. Results are robust to reasonable variations of the number of lags (results available upon request).

Given its high non-linearity, the model is estimated by the Monte-Carlo MarkovChain simulation method proposed by Chernozhukov and Hong (2003). ${ }^{8}$ Notice that the indicator variable $z_{t}$ is not embedded in our vector of modeled variables $\boldsymbol{X}_{t}$. As

\footnotetext{
${ }^{7}$ This implies labeling as "recessions" periods in which $z_{t} \leq-0.91$. Our results are robust to alternative calibrations for $\gamma$ implying a frequency of recessions ranging from 10 to 25 percent, where the lower bound is determined by the minimum amount of observations each regime should contain according to Hansen (1999).

${ }^{8}$ Details on the estimation methodology are reported in Caggiano, Castelnuovo, and Groshenny (2013). Note that, in principle, this model could be estimated by maximum-likelihood. However, as pointed out by Auerbach and Gorodnichenko (2012) and Teräsvirta and Yang (2013), finding the optimum of the target function may be problematic due to its flatness in some directions and its many local optima. The algorithm put forth by Chernozhukov and Hong (2003) has two attractive features in our set-up: i) it finds the global optimum of the likelihood of the model as well as distributions of the parameter estimates under general conditions; ii) it is computationally efficient. An alternative to the MCMC pursued in our paper is the search of suitable starting values for the vector of parameters of interest (Teräsvirta and Yang, 2013).
} 
discussed in Koop, Pesaran, and Potter (1996), absent any feedback from the endogenous variables to $z_{t}$, the impulse responses to an uncertainty shock can be computed by assuming regime-specific linear VARs. In other words, the macroeconomic reactions to uncertainty shocks are computed by assuming to start in a recession and to remain in such a state, i.e., the probability to switch to a non-recessionary phase is set to zero. This choice is justified by our interest to focus on the short-run dynamics of the U.S. economic system. Moreover, it has some desirable implications, i.e., the impulse responses will depend neither on initial conditions nor on the size or sign of the uncertainty shock. To give some statistical support to our choice, the estimated uncertainty shocks (conditional on our linear VAR) are regressed on a constant and three lags of the transition variable. The p-value associated to the F-test on the predictive power of the transition variable as for future uncertainty shocks reads 0.10 . The reason behind this result is the presence of the unemployment rate in our VAR. This hypothesis is corroborated by estimating uncertainty shocks with a trivariate VAR featuring uncertainty, inflation, and the federal funds rate only. When regressing such 'shocks' obtained with this model without unemployment, the p-value turns out to be 0.03 , an evidence supporting our conjecture on the informativeness of the unemployment rate in our VAR. Further considerations on the computation of our impulse responses are proposed in our Robustness checks Section.

It is worth stressing that our STVAR framework exploits information coming from all the observations in the dataset, which are "indexed" by the transition function $F\left(z_{t}\right)$. Differently, the estimation of two different VAR models (one for each given regime) would imply more imprecise estimates due to the smaller number of observations, especially for recessionary periods.

Focus on recessions. The focus of our analysis is on recessions. Two reasons lie behind this choice. First, peaks in uncertainty measures often occur during recessions. 
Differently, expansionary phases are characterized by "heterogeneous signals" associated with any measure of uncertainty (e.g. high vs. low realizations with respect to their sample means). Figure 2 plots four indicators of uncertainty often employed in empirical studies, i.e., the VIX (a volatility index related to the U.S. stock market), widely used as a proxy for uncertainty at a macroeconomic level (e.g., Bloom, 2009, Leduc and Liu, 2013); a common macro uncertainty factor estimated by Jurado, Ludvigson, and Ng (2015), which is a factor modeling the one-year ahead forecast error related to a large dataset of U.S. data; the Corporate Bond Spread (computed as the difference between the Baa 30 year-yield and the Treasury yield at a comparable maturity), employed by Bachmann, Elstner, and Sims (2013); and the Economic Policy Uncertainty index developed by Baker, Bloom, and Davis (2013), which is based on information coming from a set of U.S. newspapers and survey data. The evolution of these indicators confirms that recessions, as identified by the NBER, are characterized by comovements in the same direction of all measures of uncertainty. In contrast, ups and downs of these indicators are far from being rare during NBER expansions. Hence, a priori, recessions seem to carry cleaner information on the effects of uncertainty shocks on the macroeconomic environment than expansions. A formal support to this conjecture is offered by a recent work by Jurado, Ludvigson, and Ng (2015), who carefully estimate uncertainty factors by modeling the variability of the purely unforecastable components of future values of a large set of economic indicators. Their estimated uncertainty factors are shown to peak in correspondence to three big post-WWII recessions (1973-74, 198182, 2007-2009). More generally, they find macro uncertainty to be higher in recessions than in non-recessions years. Finally, while the identification of recessions appears to be uncontroversial in the literature, the identification of expansionary phases has proved to be debatable. In particular, the traditional two state-classification of the U.S. business cycle based on the identification of recessions and expansions has been challenged by, 
among others, Sichel (1994), van Dijk and Franses (1999), Galvão (2002), and Morley, Piger, and Tien (2013). These authors have uncovered different dynamics of business cycle indicators during "non-recessionary" phases, which have led them to model the U.S. economy with more than two states. These considerations motivate our focus on recessions.

\section{Results}

Figure 3 plots the estimated dynamic responses to a one standard deviation-shock to uncertainty (here approximated with the VIX) conditional on a linear formulation of the VAR. ${ }^{9}$ Unemployment increases significantly and persistently, and follows a humpshaped path before going back to its steady-state value. The reaction of inflation is negative, though it is hardly significant. The policy rate decreases significantly after the shock for a limited number of quarters, following a pattern consistent with a flexible inflation targeting strategy by the Federal Reserve. These results are in line with those obtained by Leduc and Liu (2013) and Basu and Bundick (2014), i.e., our linear model suggests that aggregate uncertainty shocks act as "demand" shocks in the sense that they temporarily open a recession and, to some extent, lower inflation.

A quantitatively very different picture emerges when non-linearities are admitted to play a role in this system. Figure 4 superimposes the dynamic responses conditional on a recessionary phase of the economy to those estimated with the linear framework. Several elements are worth noting. First, the reaction of unemployment is much larger during recession. The linear VAR model predicts that an exogenous increase of the VIX may be followed by a reaction of the unemployment rate of about 0.17 percentage points four quarters after the shock, and of about 0.14 percentage points eight quarters after

\footnotetext{
${ }^{9}$ Caggiano, Castelnuovo, and Groshenny (2013) show that our results are robust to using alternative indicators of uncertainty like the macro uncertainty factor computed by Jurado, Ludvigson, and $\mathrm{Ng}$ (2015) as well as the Corporate Bond Spread considered by Bachmann, Elstner, and Sims (2013).
} 
such shock. The non-linear VAR reveals that the same shock, when hitting the economic system during a recession, is estimated to induce an increase of unemployment of 0.36 percentage points four quarters after the shock, and 0.41 two years after the shock. The difference is statistically significant. This suggests that uncertainty shocks may exert quite a severe impact on unemployment when the economy is already experiencing a recession. Somewhat not surprisingly (in light of a possible Phillips curve-related reading of U.S. inflation dynamics), the reaction of inflation is also predicted to be larger after the shock. As in the linear case, monetary policy (whose stance is here captured by the federal funds rate) reacts according to a flexible inflation targeting strategy. Similarly to inflation and unemployment, the federal funds rate is estimated to be more sensitive to uncertainty shocks during recessions. Admittedly, the differences between the responses based on our linear VAR and those associated to recessions are likely to be over-estimated by the assumption of no switch from the recessionary phase. One should therefore interpret the estimated responses under recessions as an upper bound, more than a mean estimate. On the other hand, the coefficients of our recessions-related VAR are estimated by using also information about the dynamics of the system in the nonrecessionary regime, a strategy which is likely to bias the non-linear estimates towards those associated to the linear VAR.

From a modeling standpoint, the non-linear VAR suggests that the relative force of different transmission channels may change over the business cycle. The overall effect on the real side of the economy and inflation is negative during recessions as well as according to the linear model. This evidence is replicable by a model featuring matching frictions in the labor market as shown by Leduc and Liu (2013), who also discuss how price stickiness may magnify the demand effects of uncertainty shocks. The quantitative difference found between our two sets of impulse responses may therefore be due to a larger impact exerted by real frictions on the labor market during recessions (e.g., lower 
likelihood to form a firm-worker match, higher probability of breaking a previously formed-match). Differently, our results cast doubts on pure RBC frameworks featuring a Walrasian labor market. In such models, uncertainty shocks generate expansions due to their effects on labor supply, which raises the level of potential output. Our analysis solidly rejects the prediction of expansionary uncertainty shocks both with linear models and with non-linear frameworks. Hence, our results lend support to the analysis proposed by Basu and Bundick (2014), who show that the introduction of price stickiness in an otherwise standard RBC framework enables their model to replicate the recessionary and deflationary effects of an exogenous increase in uncertainty.

\section{Robustness checks}

Our exercises suggest that uncertainty shocks are important for the U.S. unemployment dynamics. However, some robustness checks are in order.

ZLB. First, our results may be due to the Zero-Lower Bound (ZLB) affecting conventional monetary policy moves concerning the nominal interest rate. The Federal Reserve has hit the zero lower bound in December 2008. Since then, it has maintained the fed funds rate at historically low levels. A number of studies have argued that the impact of uncertainty shocks might be substantially more pronounced when the ZLB binds (Basu and Bundick, 2012; Johannsen, 2013). The model is then estimated by considering the sample 1962Q3-2008Q3, which excludes the years of the Great Recession affected by the presence of the ZLB. Figure 5 shows our results. In absence of ZLB, the response of unemployment is weaker and shorter-lived. Its peak response under recessions is equal to 0.30 percentage points and occurs five quarters after the shock vs. a peak equal to 0.42 percentage points occurring six quarters after the shock in the baseline scenario. Consistently, the maximum (in absolute value) reaction of the policy rate in recessions is estimated to be -0.71 percentage points when the observa- 
tions about the ZLB are included in the sample vs. about -0.92 percentage points when they are excluded. Interestingly, in absence of the ZLB, the path of the unemployment rate suggests a possible "overshoot" some ten quarters after the shock. This evidence points to the possibility of a "wait-and-see" type of behavior by firms in presence of an increase in uncertainty (Bloom, 2009). Our results suggest that the presence of the ZLB may indeed magnify the macroeconomic effects of uncertainty. Hence, our findings lend support to the theoretical predictions put forth by Basu and Bundick (2012) and Johannsen (2013) on the stronger macroeconomic effects of uncertainty shocks in presence of the ZLB.

Alternative indicators of macroeconomic "activity". Our analysis focuses on the unemployment rate. While being of clear interest from a policymaking standpoint, this variable is affected by measurement issues due to time-varying labor market participation. Moreover, it has some very low frequency movements. Several experiments with a variety of alternative indicators of macroeconomic "activity" are conducted. In particular, we rotate series of hours, output, investment, durable consumption, and non-durable consumption in one at a time and estimate four-variate VARs with these alternative series $\boldsymbol{X}_{t}^{a c t i v i t y}=\left[\text { vix } x_{t}, \pi_{t} \text {, activity }, R_{t}\right]^{\prime}{ }^{10}$ Figure 6 displays the responses of our alternative measures of real activity to an uncertainty shock. Clearly, our evidence on a larger impact of uncertainty shocks on real activity extend to all these alternative indicators of the business cycle. Interestingly, our evidence points to a "drop, rebound, and overshoot" effect of uncertainty shocks, which is consistent with a "wait-and-see" optimal behavior in response to an increase in uncertainty (Bloom, 2009).

Omitted variables/Cholesky ordering. Our results may be spurious in presence

\footnotetext{
${ }^{10}$ The variables considered are hours of all persons of the nonfarm business sector, real GDP, real private nonresidential fixed investment, real personal consumption expenditures - durable goods, and real personal consumption expenditures - nondurable goods plus services. We control for the different degree of integration of these series with respect to the remaining variables in our VAR by considering the former in log-deviations with respect to a cubic trend. Our main finding on larger real effects of uncertainty shocks during recessions is robust to working with these series in growth rates.
} 
of misspecification of the econometric model. If our VAR does not embed sufficient information to consistently estimate the uncertainty shocks, the impulse responses could be distorted and, possibly, spuriously magnify the role of such shocks. Variables endowed with relevant information for modeling the shock of interest and/or the interactions among the variables may be omitted from the VAR. Several examples of potentially relevant but omitted variables are provided by the literature. For instance, consumer sentiment may be important for explaining households' decisions and influence labor supply, therefore affecting production and unemployment. VARs may also miss anticipated effects of uncertainty shocks. Christiano, Motto, and Rostagno (2014) show that, in an estimated DSGE model of the business cycle with a number of real, nominal, and financial frictions, anticipated risk (uncertainty) shocks (measured as the evolution of cross-sectional dispersion of firms' capital efficiency) greatly improve their model's descriptive power. This implies that VAR one-step ahead forecast errors of empirical measures of uncertainty may confound unexpected movements of the level of uncertainty with expected ones. Both the first and the second type of informational insufficiency may be tackled by expanding our baseline vector to include possibly omitted variables for better capturing the correlations in the data as well as for modeling agents' expectations over future (and known) realizations of the relevant shocks. Another issue regards our identification strategy, which relies on a Cholesky decomposition conditional on a vector with uncertainty ordered first. Despite being quite popular in the literature, this assumption is debatable. The robustness of our results to various perturbations of the baseline vector is checked. Such perturbations are presented and motivated below.

S\&P500. Our baseline analysis identifies uncertainty shocks by isolating exogenous movements of the VIX. Such index captures the volatility of the stock market. Of course, variations of the level of the stock market per se may be important determinant of aggregate demand and inflation (for instance, because of financial wealth-related effects 
in a sticky-price context as in Castelnuovo and Nisticò, 2010). Since in our sample the correlation between the VIX and the log of the S\&P500 is 0.28 , our baseline model might mix up variations in uncertainty with variations in the level of the stock market index. We then consider the five-variate $\operatorname{VAR} \boldsymbol{X}_{t}^{S \& P 500}=\left[S \& P 500_{t}, v i x_{t}, \pi_{t}, u n_{t}, R_{t}\right]^{\prime}$, where "S\&P500" captures the log of S\&P500 (source: Federal Reserve Bank of St. Louis' website). ${ }^{11}$

TFP. Bachmann and Bayer (2013) propose a model in which shocks to firms' profitability risk, propagated via capital adjustment costs, have the potential to be a major source of business cycle fluctuations. Using a rich German firm-level dataset, they find that such a shock, when taken in isolation, leads firms to adopt a "wait-and-see" strategy for investment. However, the contribution of this shock to the forecast error variance of investment, output, and total hours is found to be limited. Interestingly, the micro-data employed by Bachmann and Bayer (2013) support a version of the model in which aggregate productivity and firm-level risk processes are correlated. In presence of this correlation, shocks to firm's profitability risk explain about one-third of the forecast error variance of output (as well as investment and hours) after ten years. This may be due to the fact that risk shocks today anticipate the future evolution of aggregate productivity, whose systematic impact on output and investment is large. Controlling for movements in TFP is therefore important to isolate the role of uncertainty shocks per se. To this aim, the following five-variate VAR is considered: $\boldsymbol{X}_{t}^{T F P}=\left[T F P_{t}, v i x_{t}, \pi_{t}, u n_{t}, R_{t}\right]^{\prime}$, where "TFP" is the log of the total factor productivity measure proposed by Fernald (2012). The series is adjusted to control for variations in factor utilization as in Basu, Fernald, and Kimball (2006). The source of the data is

\footnotetext{
${ }^{11}$ The S\&P500 displays a distinct up-trending behavior in the sample. Our VAR is estimated by employing a cubically detrended measure of (the log of) S\&P500. Bloom (2009) and Jurado, Ludvigson, and $\mathrm{Ng}$ (2015) Hodrick-Prescott filter the log of the S\&P500 index to isolate its cyclical component. Our results are similar when a Hodrick-Prescott filter (smoothing weight: 1,600) is applied to the stock market index.
} 
the Federal Reserve Bank of San Francisco's website. ${ }^{12}$

Consumer sentiment. Uncertainty and consumer confidence also go hand-inhand, and share some information concerning agents' expectations over the future evolution of the economic system. An often employed measure of consumer sentiment is the index of consumer expectations based on information collected via the Michigan Survey of Consumers. The index is calculated as an average of the results coming from three different questions concerning the future evolution of the business cycle (expectations about aggregate business conditions over the next year; expectations about aggregate business conditions over the next five years; expectations about personal financial conditions over the next year). Bachmann and Sims (2012) estimate the systematic effects due to this measure of consumer "confidence" for the transmission of fiscal policy shocks to the business cycle and find it to be substantial, especially during recessions. The correlation between the VIX and this measure of confidence equals -0.29 in our sample. Hence, once may fear that our uncertainty shocks may proxy confidence shocks, rather than representing genuine exogenous variations of uncertainty. This issue is scrutinized by estimating the five-variate $\operatorname{VAR} \boldsymbol{X}_{t}^{s e n t}=\left[\operatorname{sent}_{t}, v i x_{t}, \pi_{t}, u n_{t}, R_{t}\right]^{\prime}$, where "sent" stands for consumer sentiment.

FAVAR. A way to tackle the informational insufficiency issue, popularized by Bernanke, Boivin, and Eliasz (2005), is to add a factor extracted from a large dataset to our VAR, so to purge the (possibly bias-contaminated) estimated shocks. A large dataset composed of 150 time-series is then considered, and extract the common factors which maximize the explained variance of such series (some information on the series of our dataset, their transformations, and the computation of the factors is provided in Caggiano, Castelnuovo, and Groshenny, 2013). Our estimation leads us to obtain six common factors, a number equivalent to the one found by Stock and

\footnotetext{
${ }^{12}$ The (log of) TFP measure is HP-filtered (smoothing weight: 1,600) to preserve the same degree of integration of the other variables in the VAR.
} 
Watson (2012) in their recent analysis on the drivers of the post-WWII U.S. economy. We then conduct a check with the Factor-Augmented Smooth-Transition VAR $\boldsymbol{X}_{t}^{f a v a r}=\left[f_{t}^{1}, v i x_{t}, \pi_{t}, u n_{t}, R_{t}\right]^{\prime}$, where " $f_{t}^{1 "}$ is the factor explaining the largest share of variance of the series in our enlarged database. ${ }^{13}$

Cholesky ordering. Finally, our assumptions to identify an exogenous variation of uncertainty implies that no macroeconomic shock can contemporaneously affect the level of uncertainty in the economic system. While being common in this literature, the assumption is nonetheless questionable. To check the extent to which this assumption may affect our results, uncertainty is ordered last in our vector, i.e., $\boldsymbol{X}_{t}^{\text {unclast }}=\left[\pi_{t}, u n_{t}, R_{t}, v i x_{t}\right]^{\prime}$. This alternative ordering allows us to "purge" the VIX by the movements due to past as well as contemporaneous shocks hitting the economic system. By construction, the macroeconomic variables modeled with our VAR are forced to have a zero on-impact reaction to uncertainty shocks.

The outcome of all robustness checks are reported in Figure 7. In all cases, the recessionary evolution of the unemployment rate is comparable to the baseline case. Admittedly, some quantitative effects are present. The vectors featuring either the measure of TFP, the factor, or the measure of consumer confidence predict a somewhat milder response of unemployment with respect to the baseline case. The vector controlling for movements in the S\&P500 index returns an even milder (but still quite substantial) short-run response of unemployment. However, as a matter of fact, all scenarios confirm the remarkable increase of unemployment in response to an uncertainty shock. The response of inflation turns out to be quite robust across scenarios, with a clear and abrupt fall in the short-run and a fairly quick rebound. The response of the

\footnotetext{
${ }^{13}$ Our first factor is just mildly correlated with the unemployment rate (-0.02). Therefore, it is likely not to represent a "redundant" variable in our VAR. Notice that, in line with a Okun's law interpretation of the relationship between real GDP and unemployment, the correlation between the first factor (whose degree of correlation with the real GDP growth rate reads 0.73) and the difference in the unemployment rate is much stronger $(-0.72)$.
} 
policy rate is estimated to be extremely robust as well. ${ }^{14}$

Importantly, the role of non-linearities turns out to be supported also by our sensitivity analysis. Figure 8 shows the difference between the predictions of linear vs. non-linear VARs in each of the cases previously shown in Figure 7. In particular, it focuses on the two policy-relevant variables in our analysis, i.e., unemployment and inflation. While some heterogeneity across scenarios may be detected, all cases under scrutiny point to a substantially deeper recession and deflationary phase after a shock when non-linearities are taken into account, and recessions are the focus of our investigation. Quantitatively, the indications coming from the VARs are very similar.

Conditionally-linear IRFs. As in Auerbach and Gorodnichenko (2012), the computation of our IRFs is undertaken by assuming to remain in a recessionary state after the uncertainty shock has hit the economic system. Ramey and Zubairy (2014) criticize Auerbach and Gorodnichenko's (2012) computation of the macroeconomic IRFs to a positive fiscal spending shock. An expansionary shock, their argument goes, is likely to help the economy out of a recession. Hence, the omission of the possibility of switching from a regime to another could be a source of bias. We believe that Ramey and Zubairy's (2013) critique hardly applies to our case. Our analysis quantifies the effects of a contractionary shock such as an exogenous increase in uncertainty on unemployment in recessions. Hence, our assumption of remaining in the same phase of the business cycle after the shock is somewhat natural. It also enables us to enjoy a computational benefit, since it simplifies the calculation of IRFs and makes them independent with respect to sign, size and history of the shocks. An experiment based on Generalized

\footnotetext{
${ }^{14}$ Bachmann and Bayer (2013) show that most of the relevance of firm-level risk shocks is due to their systematic interaction with aggregate productivity. Our results are confirmed by an exercise in which the systematic impact of uncertainty shocks on TFP is set to zero in the VAR. Admittedly, the discrepancy between our results and Bachmann and Bayer's (2013) may be due to the inability of our VAR to correctly capture the "structural" correlation between risk and aggregate productivity. Moreover, our measure of aggregate uncertainty differs from Bachmann and Bayer's, which is constructed with a detailed dataset referring to German firms. The exploration of the relationships among firm risk, aggregate uncertainty, and aggregate productivity is left to future research.
} 
IRFs that account for the feedback going from the evolution of our transition variable (included in our set of endogenous variables in this experiment) to the probability of recession shows that our main result, i.e., that the real effects of uncertainty shocks are larger in recessions, turns out to be fully confirmed (see Caggiano, Castelnuovo, and Groshenny, 2013).

\section{$5 \quad$ FEVDs}

Finally, the contribution of uncertainty shocks for the dynamics of the variables of interest by performing a forecast error variance decomposition is assessed. Table 1 collects figures concerning our eight quarter-ahead investigation. Conditional on the linear VAR, uncertainty shocks are estimated to be responsible for an important share of the variance of unemployment (23\%), but negligible for inflation (1\%) and the policy rate $(2 \%)$. Quite differently, conditional on recessions uncertainty shocks contribute three times as much to the variance of unemployment (62\%), and explain a substantial chunk of the variance of the policy rate $(41 \%)$. The contribution of inflation is also much larger $(8 \%)$ than estimated with a linear model.

To appreciate the role of uncertainty shocks, Table 1 also reports the estimated contribution of monetary policy shocks, which are identified with a standard Cholesky scheme. The linear model suggests a large contribution to the variance of the policy rate (49\%), and a moderate one as for unemployment (5\%) and inflation (1\%). The nonlinear model predicts a milder contribution of policy shocks on unemployment (1\%). Some lessons can be drawn from this variance decomposition analysis. First, uncertainty shocks importantly contribute to the dynamics of unemployment in recessions. Second, linear models may lead to an underestimation of the contribution of uncertainty shocks, a finding in line with our impulse response function analysis. Third, uncertainty shocks turn out to be more important than monetary policy shocks in ex- 
plaining the dynamics of unemployment. Incidentally, we notice that monetary policy shocks are estimated to be more powerful (as for their effects on unemployment) in "normal times" (here approximated by our linear model, which mixes up recessions and non-recessionary phases) than during recessions. This finding lines up with the recent analysis by Vavra (2014). He studies price-setting models with volatility shocks, and shows that greater volatility leads to an increase in aggregate price flexibility. Consequently, a nominal stimulus mostly generates inflation rather than output growth. Since volatility is countercyclical, this implies that monetary stimulus has smaller real effects during recessions. Vavra (2014) shows that his models matches a variety of facts in CPI micro data that standard price-setting models miss. Empirical support to the prediction of policy shocks being less important for the dynamics of the real side of the economy when uncertainty is high is also offered by Aastveit, Natvik, and Sola (2013) and Pellegrino (2014), who work with non-linear VARs and macroeconomic data for a number of countries, including the United States.

One potential issue to take into account is that the estimated contribution of uncertainty shocks to the variance of the forecast error of unemployment might be biased due to the lack of relevant information in our baseline VAR. Table 2 collects the contribution of uncertainty shocks conditional on our five-variate model with S\&P500, and contrasts them to those shown in Table 1. Perhaps not surprisingly, the five-variate VAR suggests a substantially lower contribution of uncertainty shocks during recessions (10\%). However, the non-linear model confirms, once again, a much more important role for uncertainty shocks than what suggested by a standard linear VAR (2\%). The same exercise conducted with our FAVAR model returns qualitatively similar results. In particular, uncertainty shocks are estimated to exert a very mild contribution to the forecast error variances of inflation and the policy rate $(1 \%)$, and a moderate contribution to unemployment rate's forecast error variance (10\%). Differently, the figures 
under recessions read 6\% (inflation), 26\% (unemployment rate), and 31\% (policy rate).

\section{Conclusions}

What are the effects of uncertainty shocks on unemployment dynamics? We answer this question by estimating non-linear (Smooth-Transition) VARs with post-WWII U.S. data. Such effects are found to be asymmetric over the business cycle. In particular, the response of unemployment conditional on recessions is documented to be substantially larger than the one predicted by a linear VAR model. Inflation is also found to display a stronger reaction during economic downturns. Such differences are shown to be robust to a variety of perturbations of our baseline vector, including different information sets, alternative measures of uncertainty, and different strategies to identify uncertainty shocks in the VARs. An implication of these findings is that linear models mixing up recessions and non-recessionary phases may substantially downplay the effects triggered by uncertainty shocks.

From a modeling standpoint, our results support frameworks with sticky prices, which have been shown to help micro-founded DSGE models to replicate the comovements involving output and its components conditional on an uncertainty shock (Basu and Bundick, 2012). Moreover, our results lend support to the modeling of real frictions on the labor market, which are key for replicating the response of unemployment to uncertainty hikes, above all when combined with nominal price frictions (Leduc and Liu, 2013). Finally, our evidence points to a stronger effect of uncertainty shocks in presence of the zero-lower bound, a prediction in line with the theoretical investigations by Basu and Bundick (2012) and Johannsen (2013).

\section{References}

Aastveit, K. A., G. J. Natvik, and S. Sola (2013): "Macroeconomic Uncertainty and the Effectiveness of Monetary Policy," Norges Bank, mimeo. 
Alexopoulos, M., and J. Cohen (2009): "Uncertain Times, Uncertain Measures," University of Toronto, Department of Economics Working Paper No. 325.

Auerbach, A., and Y. Gorodnichenko (2012): "Measuring the Output Responses to Fiscal Policy," American Economic Journal: Economic Policy, 4(2), 1-27.

Bachmann, R., And C. Bayer (2013): "Wait-and-See" Business Cycles," Journal of Monetary Economics, 60(6), 704-719.

Bachmann, R., S. Elstner, and E. Sims (2013): "Uncertainty and Economic Activity: Evidence from Business Survey Data," American Economic Journal: Macroeconomics, 5(2), 217-249.

Bachmann, R., And G. Moscarini (2012): "Business Cycles and Endogenous Uncertainty," RWTH Aachen University and Yale University, mimeo.

Bachmann, R., and E. Sims (2012): "Confidence and the transmission of government spending shocks," Journal of Monetary Economics, 59, 235-249.

Baker, S., and N. Bloom (2013): "Does Uncertainty Reduce Growth? Using Disasters As Natural Experiments," NBER Working Paper No. 19475.

Baker, S., N. Bloom, and S. J. Davis (2013): "Measuring Economic Policy Uncertainty," Stanford University and the University of Chicago Booth School of Business, mimeo.

BASU, S., AND B. Bundick (2014): "Uncertainty Shocks in a Model of Effective Demand," Federal Reserve Bank of Kansas City Research Working Paper No. 14-15.

Basu, S., J. Fernald, and M. Kimball (2006): "Are Technology Improvements Contractionary?," American Economic Review, 96, 1418-1448.

Beetsma, R., and M. Giuliodori (2012): "The changing macroeconomic response to stock market volatility shocks," Journal of Macroeconomics, 34, 281-293.

Benati, L. (2013): "Economic Policy Uncertainty and the Great Recession," University of Bern, mimeo.

Benigno, G., P. Benigno, and S. Nisticò (2012): "Risk, Monetary Policy and the Exchange Rate," NBER Macroeconomics Annual, 26, 247-309.

Berger, D., And J. Vavra (2014): "Measuring How Fiscal Shocks Affect Durable Spending in Recessions and Expansions," American Economic Review Papers and Proceedings, 104(5), 112-115.

Bernanke, B., J. Boivin, And P. Eliasz (2005): "Measuring Monetary Policy: A Factor Augmented Vector Autoregressive (FAVAR) Approach," Quarterly Journal of Economics, 120(1), 387-422.

Bianchi, F., and L. Melosi (2013): "Dormant Shocks and Fiscal Virtue," NBER Macroeconomics Annual, forthcoming.

Bloom, N. (2009): "The Impact of Uncertainty Shocks," Econometrica, 77(3), 623685 . 
Bloom, N., J. Fernández-Villaverde, and M. Schneider (2013): "The Macroeconomics of Uncertainty and Volatility," Journal of Economic Literature, in preparation.

Bloom, N., M. Floetotto, N. Jaimovich, I. Saporta-Eksten, and S. J. Terry (2014): "Really Uncertain Business Cycles," Stanford University, mimeo.

Caggiano, G., E. Castelnuovo, and N. Groshenny (2013): "Uncertainty Shocks and Unemployment Dynamics: An Analysis of Post-WWII U.S. Recessions," University of Padova, Marco Fanno Working Paper No. 166-2013.

Castelnuovo, E., And S. Nisticò (2010): "Stock Market Conditions and Monetary Policy in a DSGE Model for the U.S.," Journal of Economic Dynamics and Control, 34(9), 1700-1731.

Chernozhukov, V., And H. Hong (2003): "An MCMC Approach to Classical Estimation," Journal of Econometrics, 115(2), 293-346.

Christiano, L., R. Motto, and M. Rostagno (2014): "Risk Shocks," American Economic Review, 104(1), 27-65.

Colombo, V. (2013): "Economic policy uncertainty in the US: Does it matter for the Euro Area?," Economics Letters, 121(1), 39-42.

Enders, W., And P. M. Jones (2013): "The Asymmetric Effects of Uncertainty on Macroeconomic Activity," University of Alabama, mimeo.

Fernald, J. (2012): "A Quarterly, Utilization-Adjusted Series on Total Factor Productivity," Federal Reserve Bank of San Francisco Working Paper No. 2012-19.

Fernández-Villaverde, J., P. Guerrón-Quintana, J. F. Rubio-Ramírez, and M. Uribe (2011): "Risk Matters: The Real Effects of Volatility Shocks," American Economic Review, 101, 2530-2561.

Galvão, A. B. (2002): "Can non-linear time series models generate US business cycle asymmetric shape?," Economics Letters, 77, 187-194.

Gilchrist, S., J. W. Sim, and E. Zakrajsek (2013): "Uncertainty, Financial Frictions, and Irreversible Investment," Boston University and Federal Reserve Board, mimeo.

Gilchrist, S., and J. Williams (2005): "Investment, Capacity, and Uncertainty: A Putty-Clay Approach," Review of Economic Dynamics, 8, 1-27.

Granger, C., And T. Teräsvirta (1993): Modelling Nonlinear Economic Relationships, Oxford University Press: Oxford.

Hansen, B. E. (1999): "Testing for Linearity," Journal of Economic Surveys, 13(5), $551-576$.

Johannsen, B. K. (2013): "When are the Effects of Fiscal Policy Uncertainty Large?," Northwestern University, mimeo.

Jurado, K., S. C. Ludvigson, and S. NG (2015): "Measuring Uncertainty," American Economic Review, 105(3), 1177-1216. 
Koop, G., M. Pesaran, and S. Potter (1996): "Impulse response analysis in nonlinear multivariate models," Journal of Econometrics, 74, 119-147.

Koop, G., and S. Potter (1999): "Dynamic Asymmetries in U.S. Unemployment," Journal of Business and Economic Statistics, 17(3), 298-312.

Leduc, S., And Z. Liu (2013): "Uncertainty Shocks are Aggregate Demand Shocks," Federal Reserve Bank of San Francisco, Working Paper 2012-10.

Luukkonen, R., P. Saikkonen, and T. Teräsvirta (1988): "Testing linearity against smooth transition autoregressive models," Biometrika, 75, 491-499.

Morley, J., And J. Piger (2012): "The Asymmetric Business Cycle," Review of Economics and Statistics, 94(1), 208-221.

Morley, J., J. Piger, and P.-L. Tien (2013): "Reproducing Business Cycle Features: Are Nonlinear Dynamics a Proxy for Multivariate Information?," Studies in Nonlinear Dynamics \&6 Econometrics, 17(5), 483-498.

Mumtaz, H., And P. Surico (2013): "Policy Uncertainty and Aggregate Fluctuations," Queen Mary University of London and London Business School, mimeo.

Mumtaz, H., and K. Theodoridis (2012): "The international transmission of volatility shocks: An empirical analysis," Bank of England Working Paper No. 463.

Nodari, G. (2014): "Financial Regulation Policy Uncertainty and Credit Spreads in the U.S.," Journal of Macroeconomics, 41, 122-132.

Pellegrino, G. (2014): "Uncertainty and Monetary Policy in the US: A Journey into Non-Linear Territory," University of Padova "Marco Fanno" Working Paper No. 184-2014.

Ramey, V. A., And S. Zubairy (2014): "Government Spending Multipliers in Good Times and in Bad: Evidence from U.S. Historical Data," University of California at San Diego and Texas A\&M University, mimeo.

SiCHEL, D. E. (1994): "Inventories and the three phases of the business cycle," Journal of Business and Economics Statistics, 12, 269-277.

Stock, J. H., And M. W. Watson (2012): "Disentangling the Channels of the 20072009 Recession," Brookings Papers on Economic Activity, pp. 81-135.

Teräsvirta, T., And Y. YANG (2013): "Specification, Estimation and Evaluation of Vector Smooth Transition Autoregressive Models with Applications," CREATES, Aaruhs University, mimeo.

VAn DiJk, D., And P. H. Franses (1999): "Modeling multiple regimes in the business cycle," Macroeconomic Dynamics, 3, 311-340.

van Dijk, D., T. Teräsvirta, and P. H. Franses (2002): "Smooth Transition Autoregressive Models - A Survey of Recent Developments," Econometric Reviews, $21(1), 1-47$.

Vavra, J. (2014): "Inflation Dynamics and Time-Varying Volatility: New Evidence and an Ss Interpretation," Quarterly Journal of Economics, 129(1), 215-258. 
Yellen, J. (2013): "Communication in Monetary Policy," speech held at the Society of American Business Editors and Writers 50th Anniversary Conference, Washington D.C, April 4. 


\begin{tabular}{lrrr}
\hline \hline Phase/Var. & inflation & unempl & pol. rate \\
\hline Uncertainty shocks & & & \\
\hline Linear & 1 & 23 & 2 \\
Recession & 8 & 62 & 41 \\
\hline Monetary policy shocks & & \\
\hline Linear & 1 & 5 & 49 \\
Recession & 1 & 1 & 29 \\
\hline
\end{tabular}

Table 1: Role of uncertainty and monetary policy shocks: 8 quarter-ahead forecast error variance decomposition. Figures conditional on our baseline VAR. Sample: 1962Q3-2012Q3.

\begin{tabular}{lrrr}
\hline \hline Phase/Var. & inflation & unempl & pol. \\
\hline Baseline model \\
\hline Linear & & & \\
Recession & 1 & 23 & 2 \\
\hline Five-variate & 8 & 62 & 41 \\
\hline Linear & 1 & 2 & 1 \\
Recession & 2 & 10 & 6 \\
\hline
\end{tabular}

Table 2: Role of uncertainty in different models: 8 quarter-ahead forecast error variance decomposition. Figures conditional on our baseline VAR and our five-variate model with the stock-market index as first variable in the vector. Sample: 1962Q3-2012Q3. 


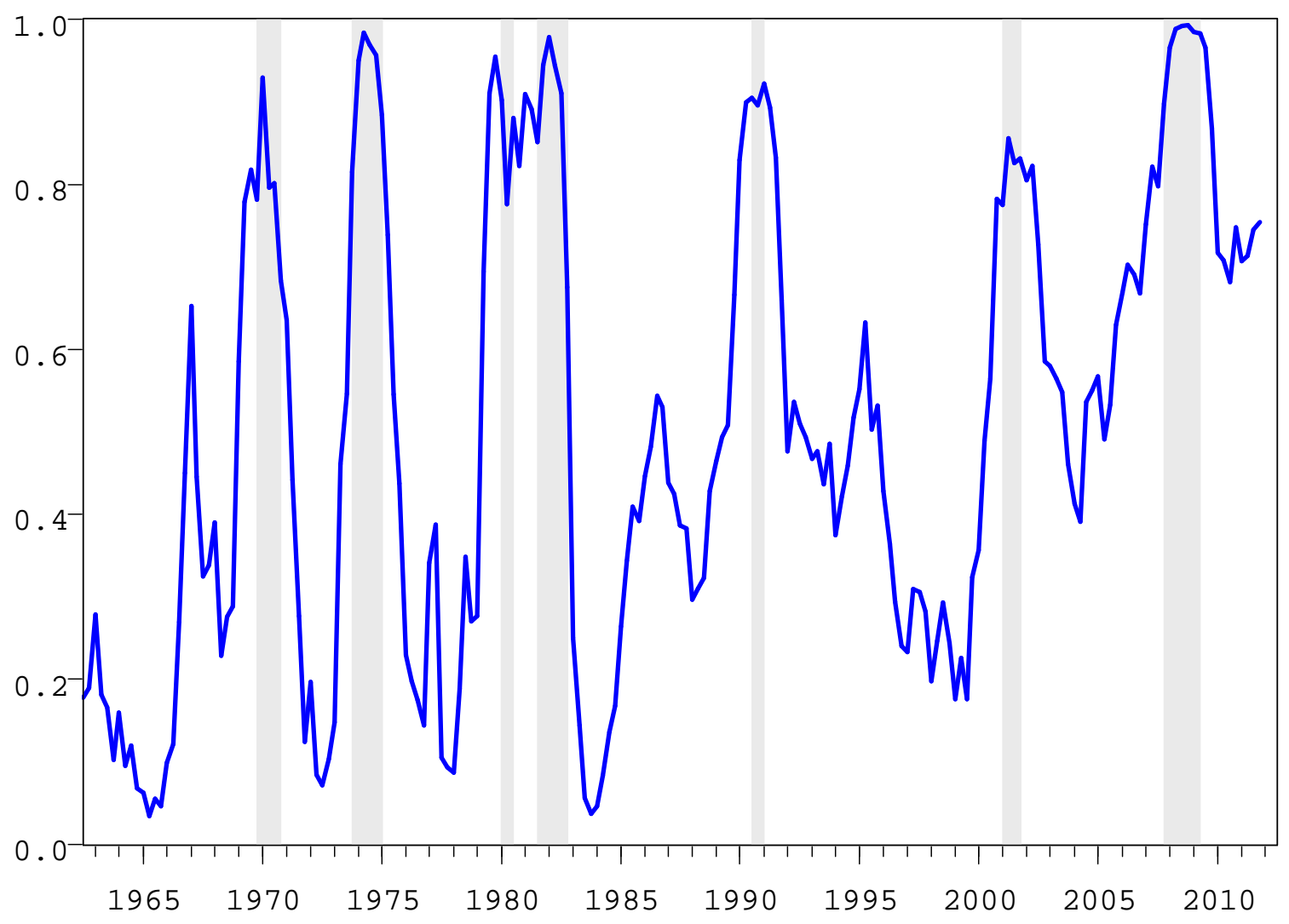

Figure 1: Probability of being in a recessionary phase. Blue line: Transition function $\mathrm{F}(\mathrm{z})$. Shaded columns: NBER recessions. 


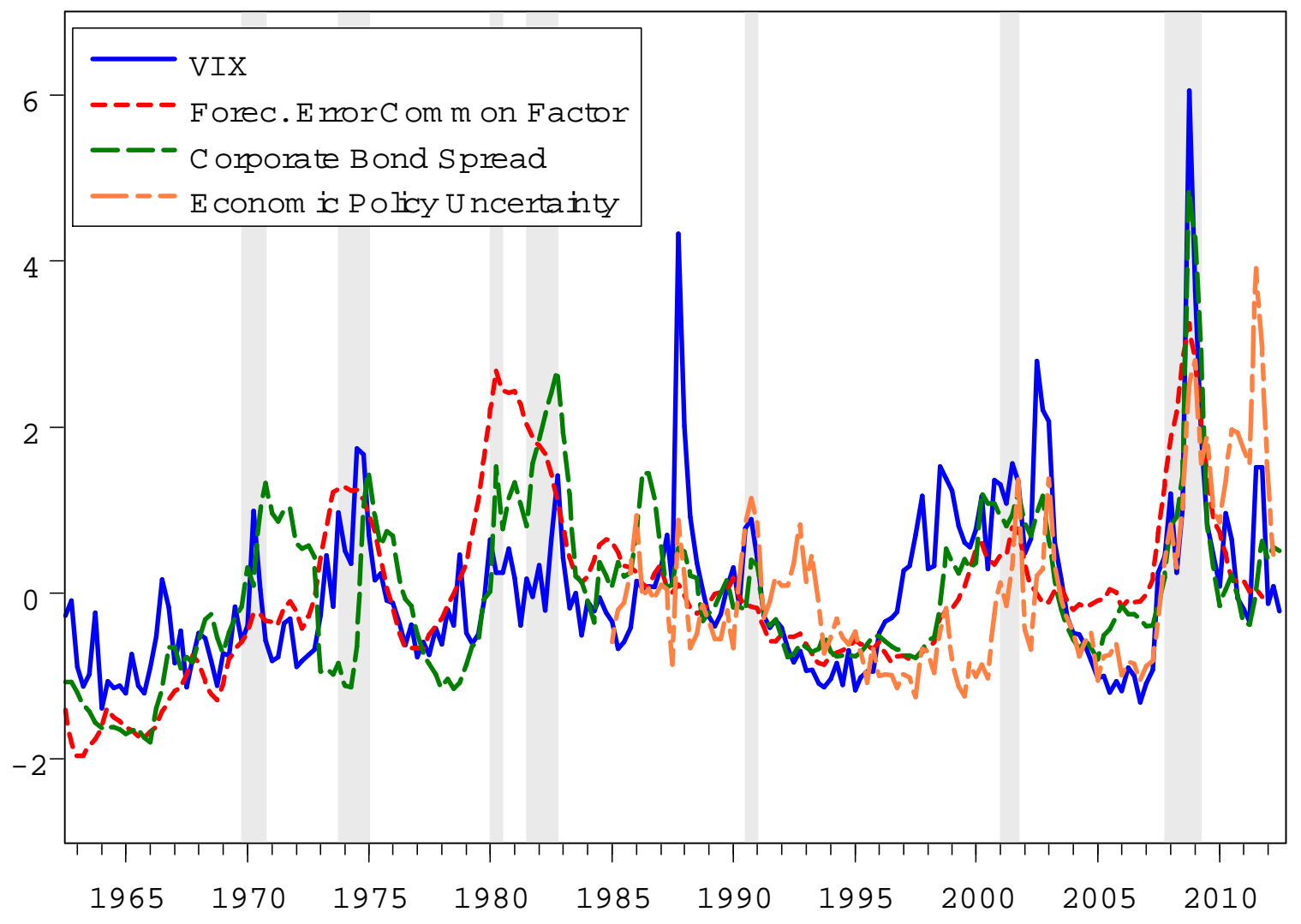

Figure 2: Uncertainty indicators. VIX: Volatility IndeX as in Bloom (2009). Forec. Error Common Factor: Common factor of the one-year ahead forecast error variance decomposition as in Jurado, Ludvigson, and Ng (2013). Corporate Bond Spread: Difference between BAA 30 year-yield and 30-year Treasury Bill yield as in Bachmann, Elstner, and Sims (2013). Economic Policy Uncertainty: index developed by Baker, Bloom, and Davis (2013). Sample: 1962Q3-2012Q3. Higher frequency-data transformed into quarterly realizations via within-the-quarter averages. Shaded columns: NBER recessions. 

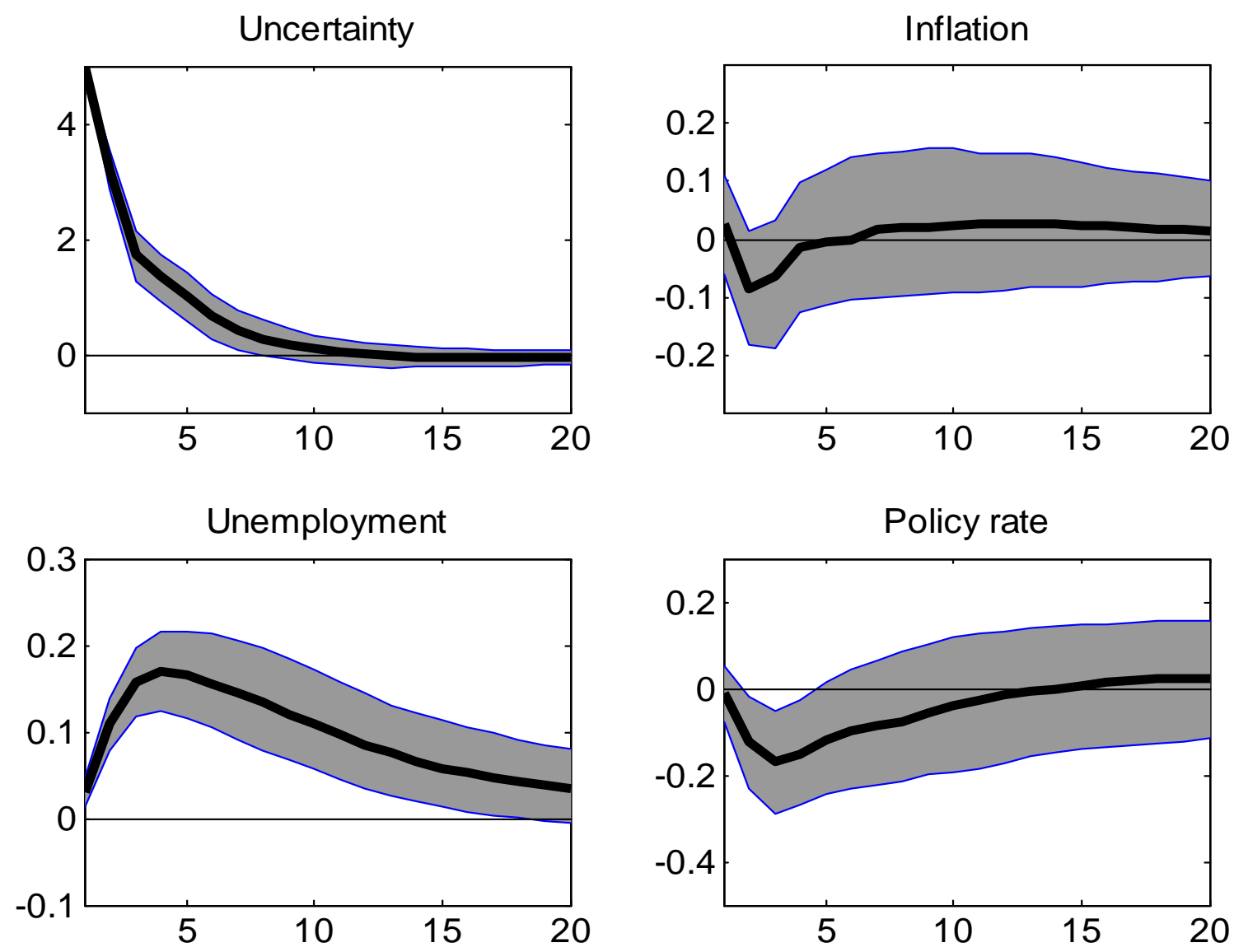

Figure 3: Macroeconomic effects of uncertainty: Linear VAR. Effects of a one standard deviation shock to VIX. Sample: 1962Q3-2012Q3. Responses predicted by a linear VAR. Baseline VAR with four variables (uncertainty, inflation, unemployment, policy rate). Gray areas: $68 \%$ bootstrapped confidence bands. Shocks identified with a Cholesky-decomposition of the variance-covariance matrix of the reduced-form residuals. 

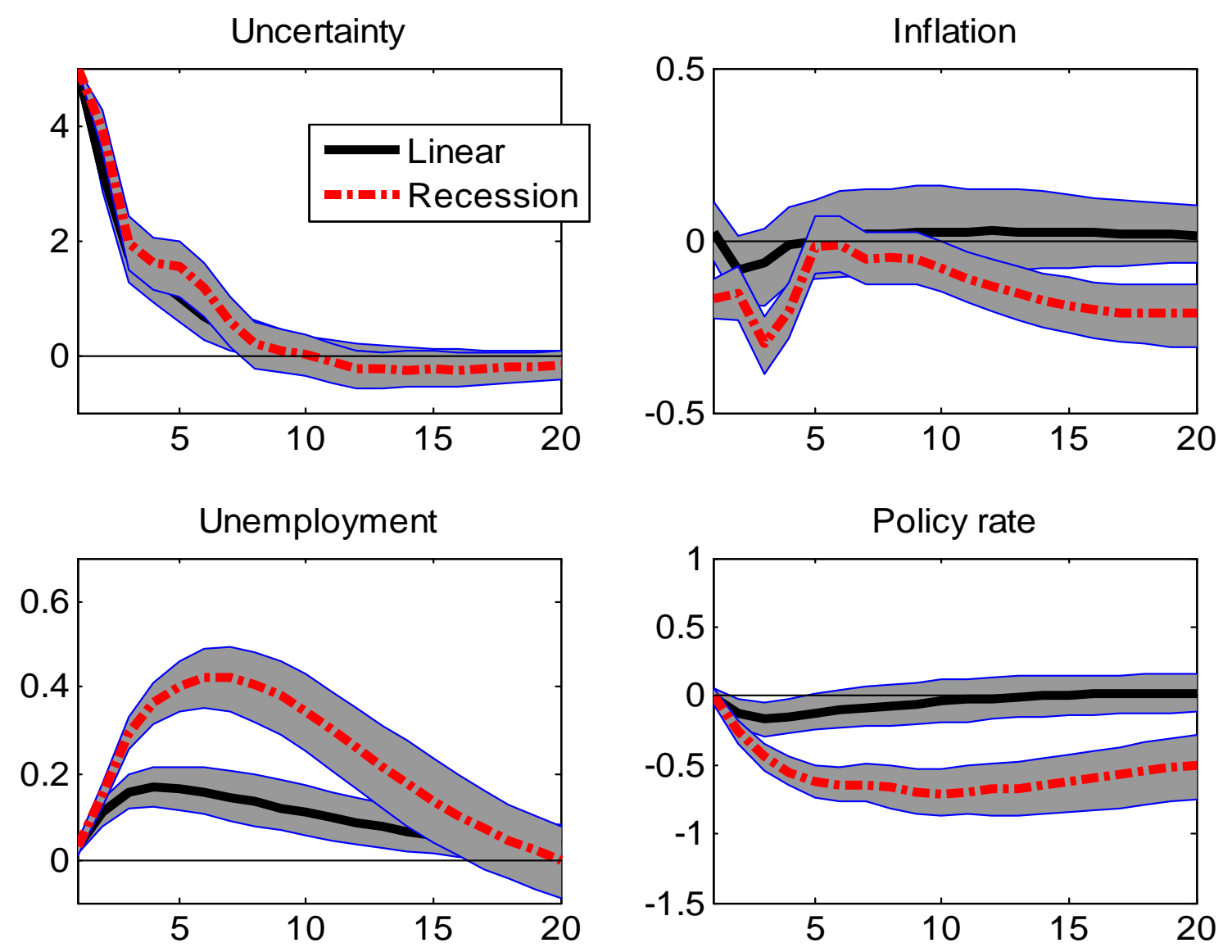

Figure 4: Macroeconomic effects of uncertainty in recessions. Effects of a one standard deviation shock to VIX. Sample: 1962Q3-2012Q3. Solid black lines: Responses predicted by a linear VAR. Dash-dotted red lines: Reactions under recessions computed with our non-linear framework. Baseline VAR with four variables (uncertainty, inflation, unemployment, policy rate). Gray areas: $68 \%$ bootstrapped confidence bands. Shocks identified with a Cholesky-decomposition of the variance-covariance matrix of the reduced-form residuals. 

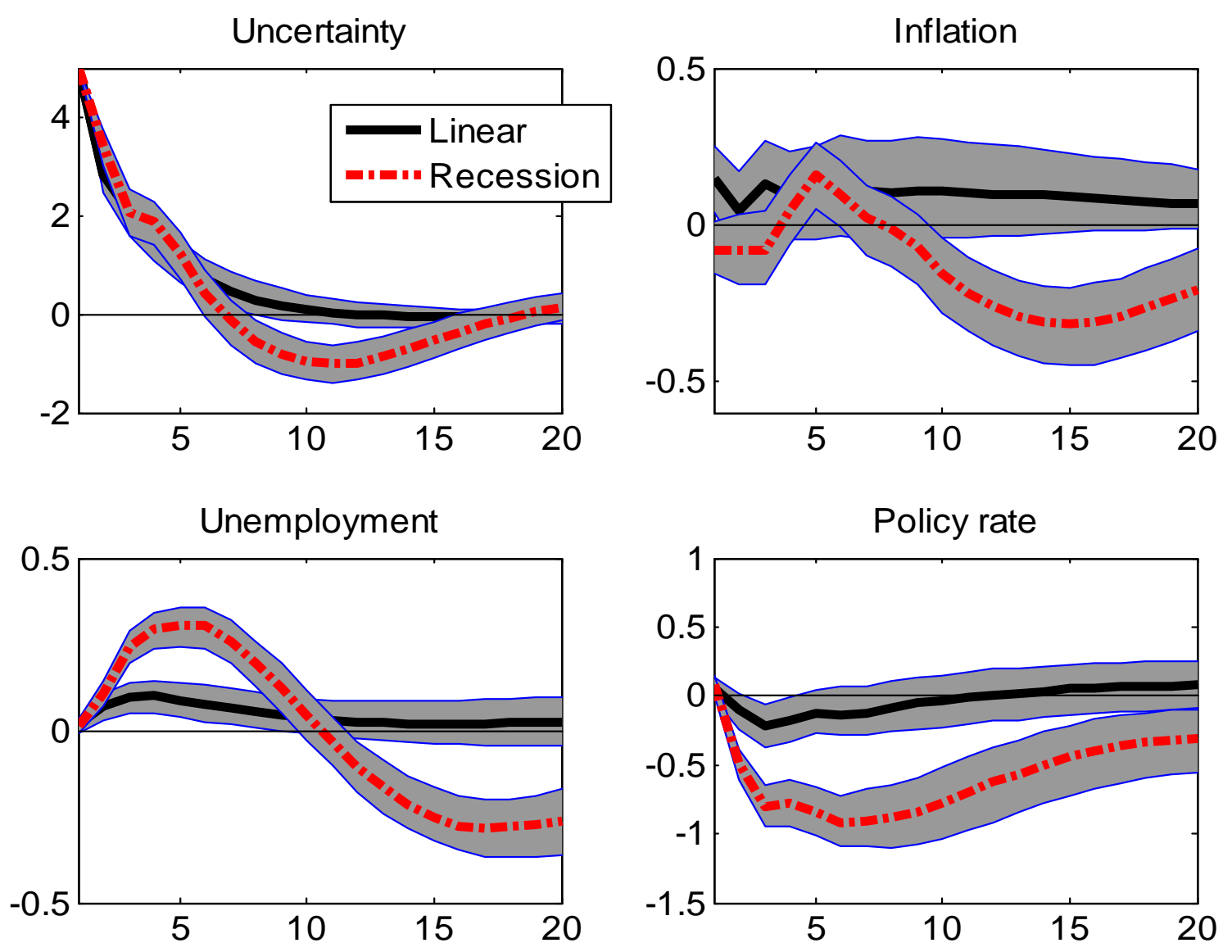

Figure 5: Macroeconomic effects of uncertainty in recessions: Pre Zero-Lower Bound sample. Effects of a one standard deviation shock to VIX. Sample: 1962Q32008Q3. Solid black lines: Responses predicted by a linear VAR. Dash-dotted red lines: Reactions under recessions computed with our non-linear framework. Baseline VAR with four variables (uncertainty, inflation, unemployment, policy rate). Gray areas: $68 \%$ bootstrapped confidence bands. Shocks identified with a Cholesky-decomposition of the variance-covariance matrix of the reduced-form residuals. 

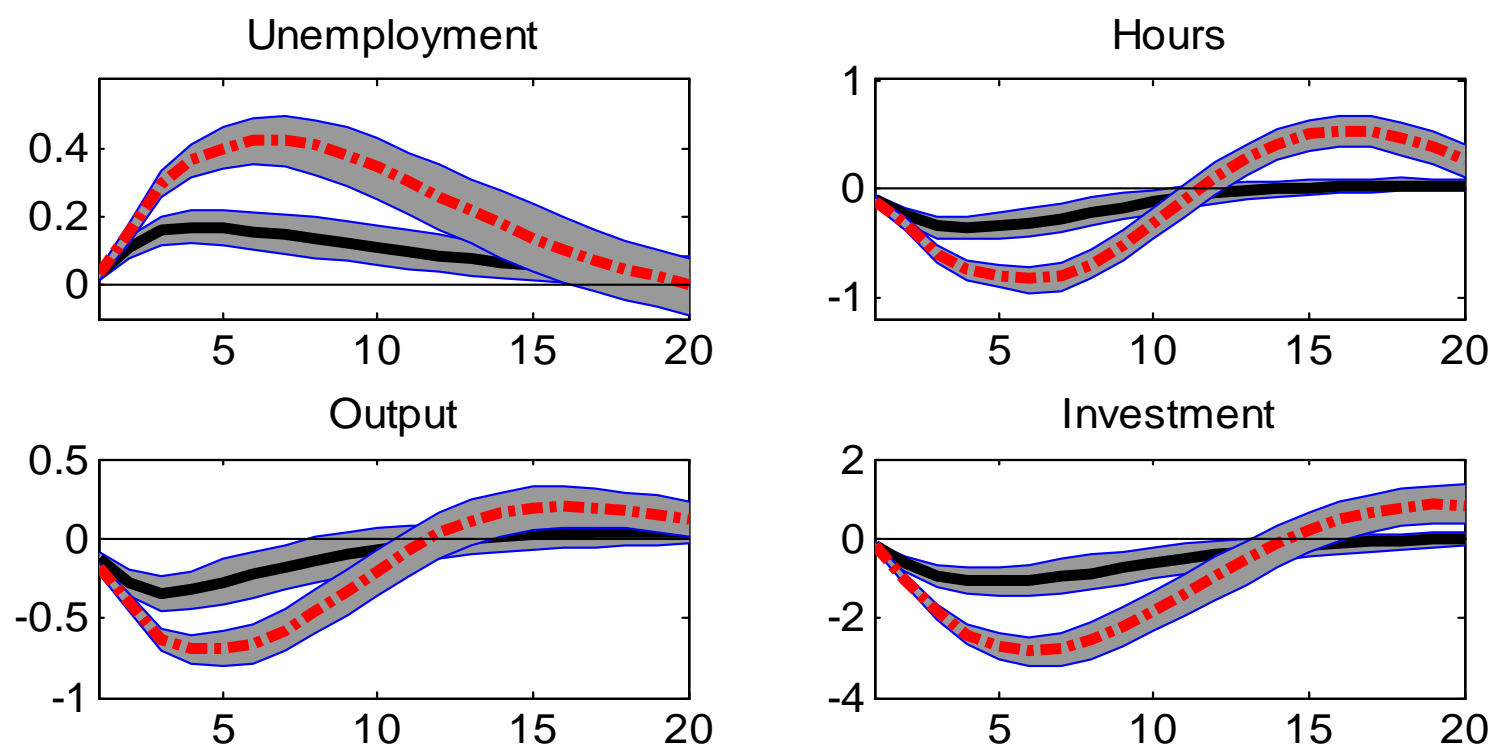

Durable Consumption

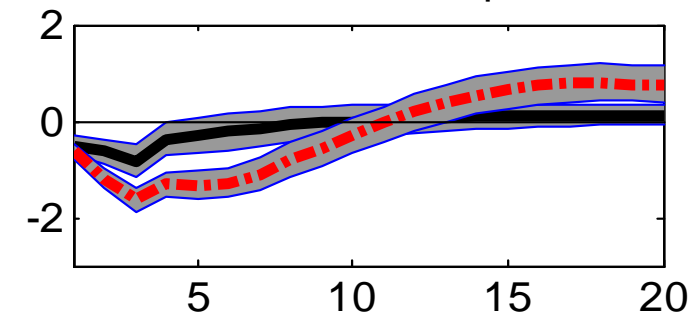

Nondurable Consumption

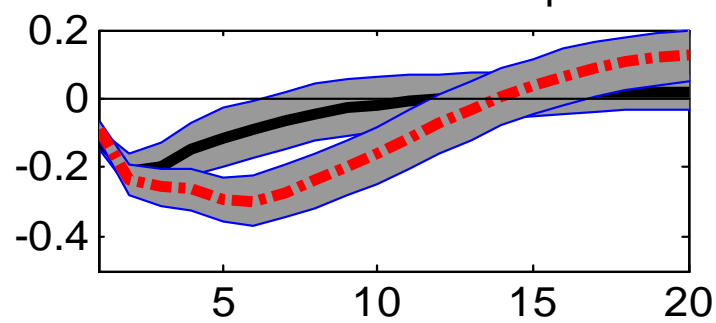

Figure 6: Macroeconomic effects of uncertainty in recessions: Real activity indicators. Effects of a one standard deviation shock to VIX. Sample: 1962Q3-2012Q3. Solid black lines: Responses predicted by a linear VAR. Dash-dotted red lines: Reactions under recessions computed with our non-linear framework. VARs with four variables (uncertainty, inflation, indicator of real activity, policy rate). Gray areas: $68 \%$ boostrapped confidence bands. Indicators of real activity considered in log-deviations with respect to a cubic trend. Shocks identified with a Cholesky-decomposition of the variance-covariance matrix of the reduced-form residuals. 

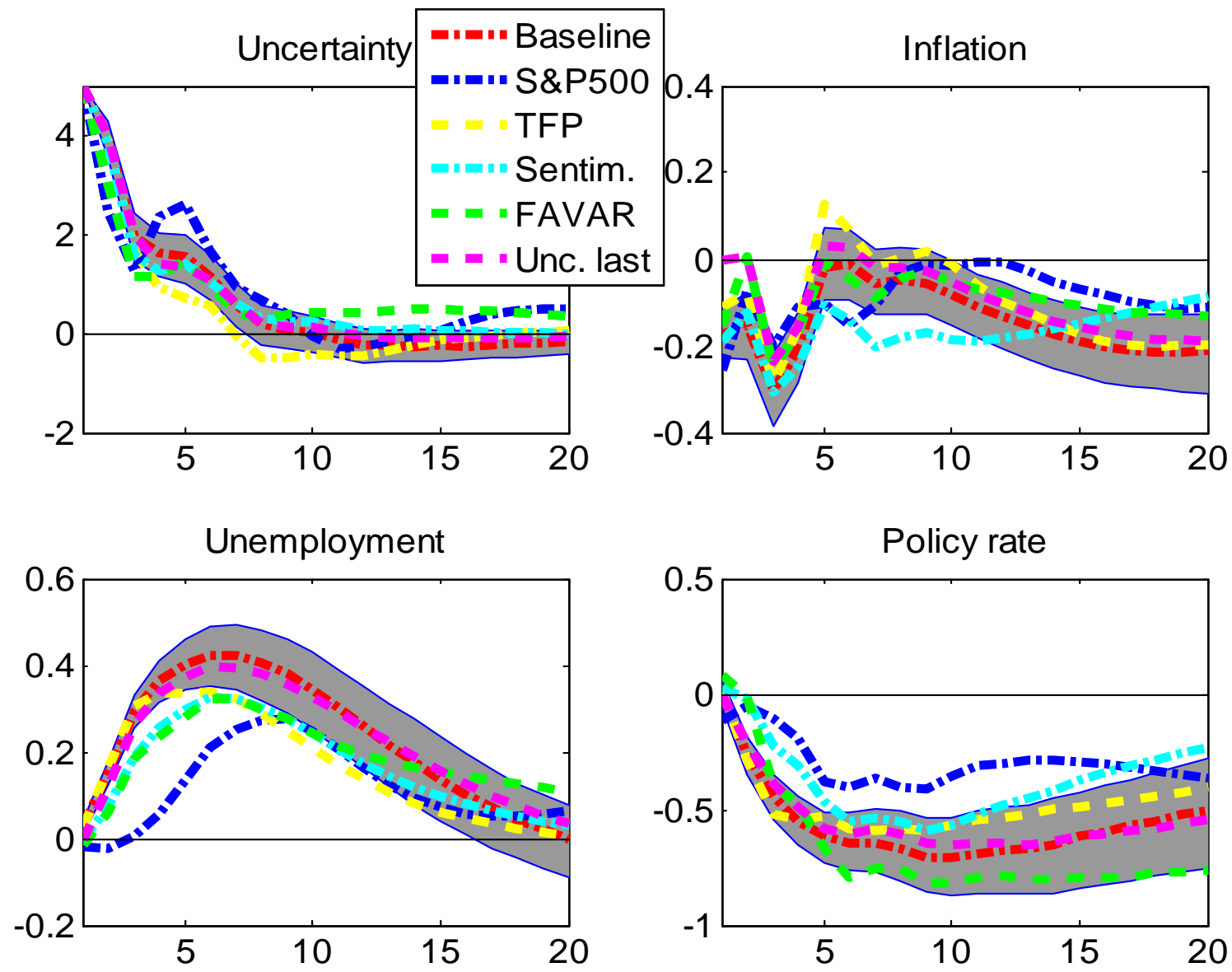

Figure 7: Macroeconomic effects of uncertainty in recessions: Robustness checks. Effects of a one standard deviation shock to VIX. Sample: 1962Q3-2012Q3. Dash-dotted red lines: Reactions under recessions computed with our non-linear framework. Baseline VAR with four variables (uncertainty, inflation, unemployment, policy rate). S\&P500: quartely observations of the (cubically detrended) log of the S\&P500 index placed on top of the baseline VAR. TFP: VAR with the utilization adjusted(log)series of TFP à la Fernald (2012) (cyclical component as isolated by the HodrickPrescott filter, smoothing weight: 1,600) on top of the variables in the baseline vector. Cons. Sent.: VAR featuring the Consumer Sentiment from the Michigan Survey placed on top of the baseline VAR. FAVAR: VAR with a common factor extracted from 150 U.S. time series placed on top of the baseline VAR. Uncert. last: Uncertainty placed last in the otherwise baseline VAR. Gray areas: $68 \%$ boostrapped confidence bands, baseline estimates. Shocks identified with a Cholesky-decomposition of the variance-covariance matrix of the reduced-form residuals. 

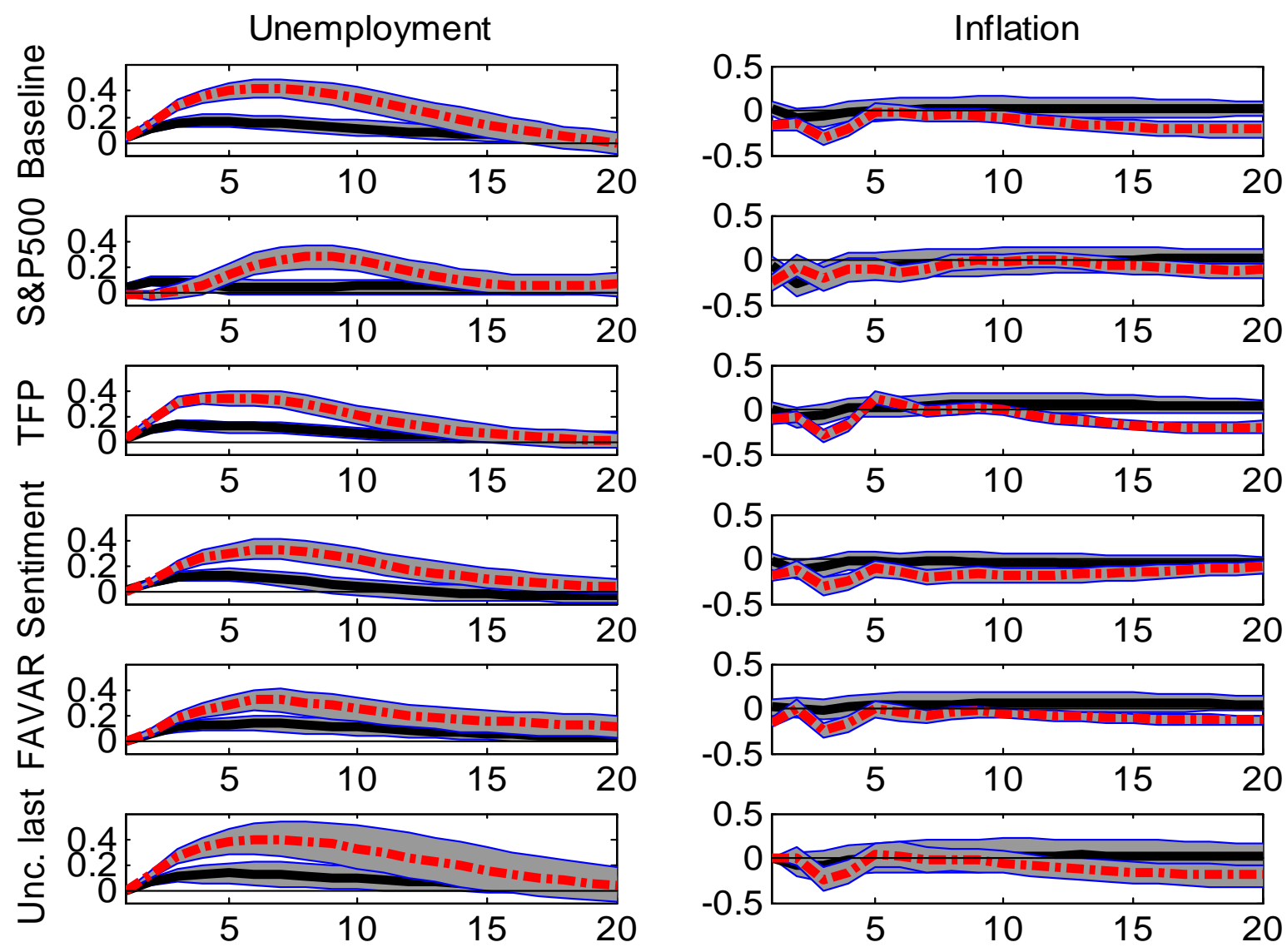

Figure 8: Robustness checks: Omitted variables/alternative orderings. Effects of a one standard deviation shock to VIX. Sample: 1962Q3-2012Q3. Solid black lines: Responses predicted by a linear VAR. Dash-dotted red lines: Reactions under recessions computed with our non-linear framework. Baseline VAR with four variables (uncertainty, inflation, unemployment, policy rate). S\&P500: quartely observations of the (cubically detrended) log of the S\&P500 index placed on top of the baseline VAR. TFP: VAR with the HP-filtered utilization adjusted-(log)series of TFP à la Fernald (2012) on top of the variables in the baseline vector. Cons. Sent.: VAR featuring the Consumer Sentiment from the Michigan Survey placed on top of the baseline VAR. FAVAR: VAR with a common factor extracted from 150 U.S. time series placed on top of the baseline VAR. Uncert. last: Uncertainty placed last in the otherwise baseline VAR. Gray areas: 68\% bootstrapped confidence bands surrounding our baseline estimates. Shocks identified with a Cholesky-decomposition of the variance-covariance matrix of the reduced-form residuals. 


\section{Appendix of "Uncertainty Shocks and Unemploy- ment Dynamics: An Analysis of Post-WWII U.S. Recessions" by Giovanni Caggiano, Efrem Casteln- uovo, Nicolas Groshenny}

This Appendix documents statistical evidence in favor of a non-linear relationship between unemployment and uncertainty. It also offers some details on the estimation of our non-linear VARs, as well as on the computation of the factors employed to perform our FAVAR estimations. Finally, it reports some extra-results, which have not been included in the paper for the sake of brevity.

\section{Statistical evidence in favor of non-linearities}

We begin our empirical analysis with a simple univariate autoregressive model for the unemployment rate, which we augment to take into account the possible non-linear role of uncertainty. The model is the following:

$$
u_{t}=c+\sum_{i=1}^{k}\left(\beta_{u, i} u_{t-i}+\beta_{v i x, i} v i x_{t-i}+\beta_{u_{-} v i x, i} u_{t-i} v i x_{t-i}\right)+\varepsilon_{t} .
$$

We estimate this model with U.S. quarterly data on unemployment and uncertainty (the latter being proxied by the VIX index) spanning the period 1962Q3-2012Q3 (a description of the data is provided later in this Section). The model is endowed with two lags for each regressor, and estimated by Ordinary-Least Squares. Our point estimates, along with our White heteroskedasticity-consistent standard errors, are displayed below: ${ }^{1}$

$$
\begin{aligned}
u_{t}= & \underset{(0.098)}{0.149}+\underset{(0.079)}{1.414} u_{t-1}-\underset{(0.073)}{0.457 u_{t-2}}+\underset{(0.004)}{0.008 v i x_{t-1}}-\underset{(0.004)}{0.002 v i x_{t-2}} \\
& \underset{(0.002)}{0.008 u_{t-1}} v i x_{t-1}+\underset{(0.002)}{0.006 u_{t-2}} \text { vix } x_{t-2}+\widehat{\varepsilon}_{t} .
\end{aligned}
$$

As shown by Luukkonen, Saikkonen, and Teräsvirta (1988), if the coefficients of the interaction terms $\beta_{u_{-} v i x, 1}$ and $\beta_{u_{-} v i x, 2}$ are non-zero, the assumption of linearity

\footnotetext{
${ }^{1}$ The absence of serial correlation of the estimated residual cannot be rejected by the BreuschGodfrey Lagrange Multiplier test, which delivers a p-value associated to the asymptotic $\chi^{2}$ distribution equal to 0.90 (with two lags of the residuals used in the regression conducted for testing purposes). Consequently, the results obtained with a Newey-West heteroskedasticity-consistent correction of the standard errors are virtually the same as those presented in the paper.
} 
in the relationship between unemployment and uncertainty is rejected by the data (see also Tsay, 1986). The p-value of a F-test conducted under the null hypothesis $H_{0}: \beta_{u_{-} v i x, 1}=\beta_{u_{-} v i x, 2}=0$ equals 0.003 , which is a clear rejection of the assumption of linearity.

To detect non-linear dynamics at a multivariate level, we apply the test proposed by Teräsvirta and Yang (2013). Their framework is particularly well suited for our analysis since it amounts to test the null hypothesis of linearity versus a specified nonlinear alternative, that of a (Vector Logistic) Smooth Transition Vector AutoRegression with a single transition variable.

Consider the following $p$-dimensional 2-regime approximate logistic STVAR model:

$$
\mathbf{X}_{t}=\Theta_{0}^{\prime} \mathbf{Y}_{t}+\Theta_{1}^{\prime} \mathbf{Y}_{t} z_{t}+\varepsilon_{t}
$$

where $\mathbf{X}_{t}=\left[v i x_{t}, \pi_{t}, u_{t}, R_{t}\right]^{\prime}$ is the $(p \times 1)$ vector of endogenous variables, vix $x_{t}$ is the VIX index, $\pi_{t}$ is inflation, $u_{t}$ is the unemployment rate, $R_{t}$ is a policy rate, $\mathbf{Y}_{t}=\left[\mathbf{X}_{t-1}|\ldots| \mathbf{X}_{t-k} \mid \boldsymbol{\alpha}\right]$ is the $((k \times p+q) \times 1)$ vector of exogenous variables (including endogenous variables lagged $k$ times and a column vector of constants $\boldsymbol{\alpha}$ ), $z_{t}$ is the transition variable, and $\boldsymbol{\Theta}_{0}$ and $\boldsymbol{\Theta}_{1}$ are matrices of parameters. In our case, the number of endogenous variables is $p=4$, the number of exogenous variables is $q=1$ and the number of lags is $k=1$ (this is due to the 'curse of dimensionality', as indicated in Teräsvirta and Yang, 2012). Under the null hypothesis of linearity, $\boldsymbol{\Theta}_{1}=\mathbf{0}$.

The Teräsvirta-Yang test for linearity versus the STVAR model can be performed as follows:

1. Estimate the restricted model $\left(\boldsymbol{\Theta}_{1}=\mathbf{0}\right)$ by regressing $\mathbf{X}_{t}$ on $\mathbf{Y}_{t}$. Collect the residuals $\tilde{\mathbf{E}}$ and the matrix residual sum of squares $\mathbf{R S S}_{0}=\tilde{\mathbf{E}}^{\prime} \tilde{\mathbf{E}}$.

2. Run an auxiliary regression of $\tilde{\mathbf{E}}$ on $\left(\mathbf{Y}_{t}, \mathbf{Z}_{1}\right)$ where $\mathbf{Z}_{1}=\left[\mathbf{X}_{t}^{\prime} z_{t}\right]$. Collect the residuals $\tilde{\boldsymbol{\Xi}}$ and compute the matrix residual sum of squares $\mathbf{R S S}_{1}=\tilde{\boldsymbol{\Xi}^{\prime}} \tilde{\boldsymbol{\Xi}}$.

3. Compute the test-statistic

$$
\begin{aligned}
L M & =\operatorname{Tr}\left\{\mathbf{R S S}_{0}^{-1}\left(\mathbf{R S S}_{0}-\mathbf{R S S}_{1}\right)\right\} \\
& =T\left(p-t r\left\{\mathbf{R S S}_{0}^{-1} \mathbf{R S S}_{1}\right\}\right)
\end{aligned}
$$

Under the null hypothesis, the test statistic is distributed as a $\chi^{2}$ with $p(k p+q)$ degrees of freedom (in our case, 20 degrees of freedom). For our model, we get $L M=34.52$, corresponding to a p-value of 0.0228 . Hence, we reject the null hypothesis of linearity at conventional confidence levels. 


\section{Estimation of the non-linear VARs}

Our model (1)-(4) is estimated via maximum likelihood. ${ }^{2}$ The model's log-likelihood reads as follows:

$$
\log L=\text { const }+\frac{1}{2} \sum_{t=1}^{T} \log \left|\boldsymbol{\Omega}_{t}\right|-\frac{1}{2} \sum_{t=1}^{T} \boldsymbol{u}_{t}^{\prime} \boldsymbol{\Omega}_{t}^{-1} \boldsymbol{u}_{t}
$$

where the vector of residuals $\boldsymbol{u}_{t}=\boldsymbol{X}_{t}-\left(1-F\left(z_{t-1}\right)\right) \boldsymbol{\Pi}_{N R} \boldsymbol{X}_{t-1}-F\left(z_{t-1}\right) \boldsymbol{\Pi}_{R} \boldsymbol{X}_{t-1}$. Our goal is to estimate the parameters $\boldsymbol{\Psi}=\left\{\gamma, \boldsymbol{\Omega}_{R}, \boldsymbol{\Omega}_{N R}, \boldsymbol{\Pi}_{R}(L), \boldsymbol{\Pi}_{N R}(L)\right\}$, where $\boldsymbol{\Pi}_{j}(L)=\left[\begin{array}{lll}\boldsymbol{\Pi}_{j, 1} & \ldots & \boldsymbol{\Pi}_{j, p}\end{array}\right], j \in\{R, N R\}$. The high-non linearity of the model and its many parameters render its estimation with standard optimization routines problematic. Following Auerbach and Gorodnichenko (2012), we employ the procedure described below.

Conditional on $\left\{\gamma, \boldsymbol{\Omega}_{R}, \boldsymbol{\Omega}_{N R}\right\}$, the model is linear in $\left\{\boldsymbol{\Pi}_{R}(L), \boldsymbol{\Pi}_{N R}(L)\right\}$. Then, for a given guess on $\left\{\gamma, \Omega_{R}, \Omega_{N R}\right\}$, the coefficients $\left\{\boldsymbol{\Pi}_{R}(L), \boldsymbol{\Pi}_{N R}(L)\right\}$ can be estimated by minimizing $\frac{1}{2} \sum_{t=1}^{T} \boldsymbol{u}_{t}^{\prime} \boldsymbol{\Omega}_{t}^{-1} \boldsymbol{u}_{t}$. This can be seen by re-writing the regressors as follows. Let $\boldsymbol{W}_{t}=\left[\begin{array}{lllll}F\left(z_{t-1}\right) \boldsymbol{X}_{t-1} & \left(1-F\left(z_{t-1}\right)\right) \boldsymbol{X}_{t-1} & \ldots & F\left(z_{t-1}\right) \boldsymbol{X}_{t-p} & \left(1-F\left(z_{t-1}\right)\right) \boldsymbol{X}_{t-p}\end{array}\right]$ be the extended vector of regressors, and $\boldsymbol{\Pi}=\left[\begin{array}{ll}\boldsymbol{\Pi}_{R}(L) & \boldsymbol{\Pi}_{N R}(L)\end{array}\right]$. Then, we can write $\boldsymbol{u}_{t}=\boldsymbol{X}_{t}-\boldsymbol{\Pi} \boldsymbol{W}_{t}^{\prime}$. Consequently, the objective function becomes

$$
\frac{1}{2} \sum_{t=1}^{T}\left(\boldsymbol{X}_{t}-\boldsymbol{\Pi} \boldsymbol{W}_{t}^{\prime}\right)^{\prime} \boldsymbol{\Omega}_{t}^{-1}\left(\boldsymbol{X}_{t}-\boldsymbol{\Pi} \boldsymbol{W}_{t}^{\prime}\right)
$$

It can be shown that the first order condition with respect to $\Pi$ is

$$
\operatorname{vec} \boldsymbol{\Pi}^{\prime}=\left(\sum_{t=1}^{T}\left[\boldsymbol{\Omega}_{t}^{-1} \otimes \boldsymbol{W}_{t}^{\prime} \boldsymbol{W}_{t}\right]\right)^{-1} \operatorname{vec}\left(\sum_{t=1}^{T} \boldsymbol{W}_{t}^{\prime} \boldsymbol{X}_{t} \boldsymbol{\Omega}_{t}^{-1}\right) .
$$

This procedure iterates over different sets of values for $\left\{\gamma, \boldsymbol{\Omega}_{R}, \boldsymbol{\Omega}_{N R}\right\}$. For each set of values, $\boldsymbol{\Pi}$ is obtained and the $\log L$ (A1) computed.

Given that the model is highly non-linear in its parameters, several local optima might be present. Hence, it is recommended to try different starting values for $\left\{\gamma, \boldsymbol{\Omega}_{R}, \boldsymbol{\Omega}_{N R}\right\}$. To ensure positive definiteness of the matrices $\boldsymbol{\Omega}_{R}$ and $\boldsymbol{\Omega}_{N R}$, we focus on the alternative vector of parameters $\boldsymbol{\Psi}=\left\{\gamma, \operatorname{chol}\left(\boldsymbol{\Omega}_{R}\right), \operatorname{chol}\left(\boldsymbol{\Omega}_{N R}\right), \boldsymbol{\Pi}_{R}(L), \boldsymbol{\Pi}_{N R}(L)\right\}$, where chol implements a Cholesky decomposition.

The construction of confidence intervals for the parameter estimates as well as the impulse responses is complicated by, once again, the non-linear structure of the problem. We compute them by appealing to a Markov Chain Monte Carlo (MCMC) algorithm

\footnotetext{
${ }^{2}$ This Section heavily draws on Auerbach and Gorodnichenko's (2012) "Appendix: Estimation Procedure".
} 
developed by Chernozhukov and Hong (2003) (CH hereafter). This method delivers a global optimum. Then, we compute confidence intervals for our IRFs with a standard bootstrapping algorithm.

Following $\mathrm{CH}$, the estimation of the model is implemented via a Metropolis-Hastings algorithm. Given a starting value $\Psi^{(0)}$, the procedure constructs chains of length $N$ of the parameters of our model following these steps:

Step 1. Draw a candidate vector of parameter values $\boldsymbol{\Theta}^{(n)}=\boldsymbol{\Psi}^{(n)}+\boldsymbol{\psi}^{(n)}$ for the chain's $n+1$ state, where $\Psi^{(n)}$ is the current state and $\boldsymbol{\psi}^{(n)}$ is a vector of i.i.d. shocks drawn from $N\left(0, \boldsymbol{\Omega}_{\Psi}\right)$, and $\boldsymbol{\Omega}_{\Psi}$ is a diagonal matrix.

Step 2. Set the $n+1$ state of the chain $\Psi^{(n+1)}=\boldsymbol{\Theta}^{(n)}$ with probability $\min \left\{1, L\left(\boldsymbol{\Theta}^{(n)}\right) / L\left(\Psi^{(n)}\right)\right\}$, where $L\left(\boldsymbol{\Theta}^{(n)}\right)$ is the value of the likelihood function conditional on the candidate vector of parameter values, and $L\left(\Psi^{(n)}\right)$ the value of the likelihood function conditional on the current state of the chain. Otherwise, set $\Psi^{(n+1)}=\Psi^{(n)}$.

The starting value $\boldsymbol{\Theta}^{(0)}$ is computed by working with a second-order Taylor approximation of the model (1)-(4), so that the model can be written as regressing $\boldsymbol{X}_{t}$ on lags of $\boldsymbol{X}_{t}, \boldsymbol{X}_{t} z_{t}$, and $\boldsymbol{X}_{t} z_{t}^{2}$. The residuals from this regression are employed to fit the expression for the reduced-form time-varying variance-covariance matrix of the VAR (see our paper) using maximum likelihood to estimate $\boldsymbol{\Omega}_{R}$ and $\boldsymbol{\Omega}_{N R}$. Conditional on these estimates and given a calibration for $\gamma$, we can construct $\boldsymbol{\Omega}_{t}$. Conditional on $\boldsymbol{\Omega}_{t}$, we can get starting values for $\boldsymbol{\Pi}_{R}(L)$ and $\boldsymbol{\Pi}_{N R}(L)$ via equation (A2).

The initial (diagonal matrix) $\Omega_{\Psi}$ is calibrated to one percent of the parameter values. It is then adjusted "on the fly" for the first 20,000 draws to generate an acceptance rate close to 0.3, a typical choice for this kind of simulations (Canova (2007)). We employ $N=50,000$ draws for our estimates, and retain the last $20 \%$ for inference.

As shown by $\mathrm{CH}, \overline{\boldsymbol{\Psi}}=\frac{1}{N} \sum_{n=1}^{N} \boldsymbol{\Psi}^{(n)}$ is a consistent estimate of $\boldsymbol{\Psi}$ under standard regularity assumptions on maximum likelihood estimators. Then, we compute the $68 \%$ confidence bands of our IRFs via a standard bootstrapping algorithm based on 500 repetitions. Our impulse responses are conditional on an uncertainty shock of size $\bar{\sigma}=5$, which is the size of the standard deviation of the uncertainty shock in the linear model. As in Auerbach and Gorodnichenko (2012) and Berger and Vavra (2014), the standardization of the size of the shock requires a normalization that, in some cases, may be problematic for the estimation of the confidence bands when applying the Chernozhukov and Hong (2003) algorithm. In short, the issue is the following. The MCMC algorithm proposes draws for each of the coefficients of the VAR, elements of the VCV under recession $\Omega_{R}$ and non-recessionary phases $\Omega_{N R}$ included. For each draw $n$, the impulse 
(column) vectors under recessions and non-recessionary phases are identified up to their sign, hence the generated chains for the Cholesky-matrices $\operatorname{chol}\left(\boldsymbol{\Omega}_{R}\right)$ and $\operatorname{chol}\left(\boldsymbol{\Omega}_{N R}\right)$ can change in signs. Although this change in signs is not a problem for estimation, it can sometimes pose a problem for the analysis of impulse responses. In particular, when there is a change in signs for the entries $[1,1]$ of $\operatorname{chol}\left(\boldsymbol{\Omega}_{R}\right)$ and $\operatorname{chol}\left(\boldsymbol{\Omega}_{N R}\right)$ that correspond to the standard deviation of the uncertainty shock, these entries can be close to zero. Given that our goal is to compute responses to a standardized uncertainty shock, we have to divide the impulse vectors [:,1] of the matrices $\operatorname{chol}\left(\boldsymbol{\Omega}_{R}\right)$ and $\operatorname{chol}\left(\boldsymbol{\Omega}_{N R}\right)$ by the draw-specific standard deviation of the uncertainty shock (and multiply it by $\bar{\sigma}=5$ ). If the entries [1,1] of $\operatorname{chol}\left(\boldsymbol{\Omega}_{R}\right)$ and $\operatorname{chol}\left(\boldsymbol{\Omega}_{N R}\right)$ are very small numbers, such divisions may give rise to large numbers, hence confidence bands may be too wide. Following Auerbach and Gorodnichenko (2012), we address this numerical issue when constructing impulse responses as follows. We draw just the VAR coefficients $\left\{\boldsymbol{\Pi}_{R}(L), \boldsymbol{\Pi}_{E}(L)\right\}$ directly from the MCMC chain $\left\{\Psi^{(n)}\right\}_{n=1}^{N}$, while we recover the covariance matrix of residuals in regime $j$ ( $j$ being either $R$ or $N R$ ) by drawing it from the distribution $N\left(\operatorname{vec}\left(\boldsymbol{\Omega}_{j}\right), \boldsymbol{\Sigma}_{j}\right)$, where

$$
\boldsymbol{\Sigma}_{j}=2\left[\left(\boldsymbol{D}_{n}^{\prime} \boldsymbol{D}_{n}\right)^{-1} \boldsymbol{D}_{n}\right]\left\{\operatorname{var}\left(\operatorname{vec}\left(\boldsymbol{\Omega}_{j}\right)\right) \otimes \operatorname{var}\left(\operatorname{vec}\left(\boldsymbol{\Omega}_{j}\right)\right)\right\}\left[\left(\boldsymbol{D}_{n}^{\prime} \boldsymbol{D}_{n}\right)^{-1} \boldsymbol{D}_{n}\right]^{\prime},
$$

$\boldsymbol{D}_{n}$ is a duplication matrix, and $\operatorname{var}\left(\operatorname{vec}\left(\boldsymbol{\Omega}_{j}\right)\right.$ is computed from $\left\{\boldsymbol{\Psi}^{(n)}\right\}_{n=1}^{N}$. This procedure is based on the discussion of the asymptotic distribution of estimated variances and covariances detailed in Hamilton (1994, Ch. 11, pp. 300-302).

\section{Computation of the factors for the FAVAR approach}

We follow Stock and Watson (2012) to estimate the factors from a large unbalanced data set of US variables. Let $\boldsymbol{X}_{t}=\left(X_{1 t}, \ldots, X_{n t}\right)^{\prime}$ denote a vector of $n$ macroeconomic time series, with $t=1, \ldots, T . X_{i t}$ is a single time series transformed to be stationary and to have mean zero. The dynamic factor model expresses each of the $n$ time series as the sum of a common component driven by $r$ unobserved factors $\boldsymbol{F}_{t}$ plus an idiosyncratic disturbance term $e_{i t}$ :

$$
\mathbf{X}_{t}=\Lambda \mathbf{F}_{t}+\mathbf{e}_{t}
$$

where $\boldsymbol{e}_{t}=\left(e_{1 t}, \ldots, e_{n t}\right)^{\prime}$ and $\boldsymbol{\Lambda}$ is the $n \times r$ matrix of factor loadings.

The factors are assumed to follow a linear and stationary vector autoregression:

$$
\boldsymbol{\Phi}(L) \boldsymbol{F}_{t}=\boldsymbol{\eta}_{t}
$$


where $\boldsymbol{\Phi}(L)$ is a $r \times r$ matrix of lag polynomials with the vector of $r$ innovations $\boldsymbol{\eta}_{t}$. Stationarity implies that $\boldsymbol{\Phi}(L)$ can be inverted and $\boldsymbol{F}_{t}$ has the moving average representation:

$$
\boldsymbol{F}_{t}=\boldsymbol{\Phi}(L)^{-1} \boldsymbol{\eta}_{t}
$$

With $n$ large, under the assumption that there is a single-factor structure, simple cross-sectional averaging provides an estimate of $\boldsymbol{F}_{t}$ good enough to treat $\widehat{\boldsymbol{F}}_{t}$ as data in a regression without a generated regressor problem. With multiple factors, Stock and Watson (2002) show that a consistent estimate of $\boldsymbol{F}_{t}$ is obtained using principal components.

Our data set is standard in the recent literature on factor models (see Forni and Gambetti (2014) and Stock and Watson, 2012). It contains an unbalanced panel of 150 quarterly series, with starting date 1947Q1 and end date 2012Q3. The data are grouped into 12 categories: NIPA variables (31); industrial production (16); employment and unemployment (14); housing starts (6); inventories, orders and sales (12); prices (15); earnings and productivity (13); interest rates (10); money and credit (12); stock prices (5); exchange rates (7); and other (9). Earnings and productivity data include TFPadjusted measures of capacity utilization introduced by Basu, Fernald, and Kimball (2006). The category labeled "other" includes expectations variables.

All series were transformed to be stationary with zero mean (see Table A1 for details). The factors were estimated using principal components as in Stock and Watson (2012). The assumption that the factors can be estimated with no breaks over the period 1947Q2-2012Q3 is motivated by the findings of Stock and Watson (2002), who show that the space spanned by the factors can be estimated consistently even if there is instability in $\boldsymbol{\Lambda}$.

\section{Data, transition probabilities, and further robustness checks}

We provide additional evidence on the data and the transition probabilities employed in our analysis, as well as about the results obtained in several other robustness checks, not reported in the paper for the sake of brevity.

Data. Figure A1 plots the four time-series we model in our baseline analysis.

Transition probability - different calibrations for the slope parameter. Figure A2 depicts the transition probability obtained by calibrating $\gamma=1.5$ as in Auerbach and Gorodnichenko (2012), Bachmann and Sims (2012), and Berger and Vavra (2014), as well as that used in the paper, i.e. $\gamma=1.75$ chosen to match the 
frequency of recessions as dated by the NBER in our sample (17\%). As shown in Figure 2 , the transition probability used in our analysis overlaps that employed in Auerbach and Gorodnichenko (2012), Bachmann and Sims (2012), and Berger and Vavra (2014) almost perfectly.

Transition probability - exercise with monthly data. A further robustness check deals with the frequency of the data (results are shown below). For such exercise, we employ monthly data and a transition probability constructed via a moving average involving twelve realizations of the growth rate of industrial production. We then recalibrate the slope parameter $\gamma=1.8$ so to replicate the frequency of recessions in the sample conditional. Figure A3 contrasts our probability of being in a recession with the NBER recessions at monthly frequencies. Our transition probability tracks well the NBER recessions in the sample under investigation, which is 1962M7-2012M9.

Alternative measures of economic activity - growth rates. In the paper we show that our results are robust to the employment of several indicators of economic activity such as hours, output, investment, durable consumption, and nondurable consumption. In the exercise documented in the paper, for these series we take log-deviations from a cubic trend to control for the possibly different degree of integration relative to that of the remaining variables included in the baseline VAR. An alternative way of dealing with this issue is to consider variables in growth rates. Figure A4 plots the responses obtained by estimating four-variate VARs including the growth rate of these alternative measures of real activity. Our main finding, that the real effect of uncertainty shocks is larger during recessions, turns out to be robust to growth rates, but it is less evident when consumption is considered, particularly as far as non-durable consumption is concerned. This exception is perhaps not surprising, because of the lower, if any, adjustment costs consumers face when deciding whether to buy a non-durable consumption good (as opposed to a durable one) or not. On the role of "wait-and-see" strategies implemented in presence of adjustment costs and higher uncertainty, see Bloom (2009). Interestingly, while observing a clear drop in all measures of economic activities, the "rebound" documented in the paper when dealing with cubically-detrended variables is not present here. We postpone an analysis on the robustness of Bloom's (2009) VAR results to different data transformation to future research.

Generalized Impulse Response Functions. Our baseline results are obtained by assuming that the economy remains in a recessionary state for twenty quarters after the shock. We check the robustness of this assumption by computing Generalized IRFs 
(GIRFs). GIRFs account for the feedback going from the evolution of our transition variable (included in our set of endogenous variables in this experiment) to the probability of being in a recession. Our main result, i.e., larger effects of uncertainty shocks in recessions, turns out to be fully confirmed by this experiment. Our GIRFs are shown in Figure A5.

Calibration of the slope parameter. Our baseline results are conditional on the calibration for $\gamma=1.75$. Results are robust to alternative calibrations for $\gamma$ implying a frequency of recessions ranging from $10 \%(\gamma=2.4)$ to $25 \%(\gamma=1.2)$, where the lower bound is determined by the minimum amount of observations each regime should contain according to Hansen (1999). Figures A6 and A7 show the impulse responses for these two alternative scenarios.

Different measures of uncertainty. So far, the analysis has hinged upon the VIX as a proxy of the macroeconomic uncertainty affecting the economic system. As discussed in Section 2, alternative proxies for uncertainty have been proposed by the literature. Jurado, Ludvigson, and Ng (2015) compute a macro uncertainty factor by modeling the common component of n-step ahead forecast error variances of 132 macroeconomic series. ${ }^{3}$ Bachmann, Elstner, and Sims (2013) consider the Corporate Bond Spread (computed as the difference between the Baa 30 year-yield and the Treasury yield at a comparable maturity). We re-run our estimates by replacing the VIX with these two measures of uncertainty (employed one at a time). As in the baseline scenario, we consider the effects of a standard deviation innovation to uncertainty.

Figure A8 compares the baseline results with those obtained with these two alternative measures of uncertainty. The responses are somewhat different from a quantitative standpoint, a fact that confirms the different information content carried by these indicators of uncertainty. In particular, the response of inflation to the Corporate Bond spread is estimated to be stronger relative to the baseline scenario, while that of unemployment slightly weaker. The reaction of unemployment to unexpected movements in the common factor computed by Jurado, Ludvigson, and $\mathrm{Ng}$ (2015) is quite similar to our baseline result. From a qualitative standpoint, all three indicators of uncertainty point to the same evidence, i.e., uncertainty hikes open a persistent recession and a de-

\footnotetext{
${ }^{3}$ Jurado, Ludvigson, and $\mathrm{Ng}(2015)$ use the method of diffusion index forecast (a forecasting model with predictors that span a rich information set) to compute the forecast errors of the 132 macroeconomic series of interest, and employ a stochastic volatility model to compute the variance of such forecast errors. As a measure of macro uncertainty, we take the common factor they computed conditional on the one year-ahead forecast error variances. The factors computed by Jurado, Ludvigson, and $\mathrm{Ng}$ (2015) with the large dataset of macro series are monthly. We create quarterly observations by taking within-quarter averages.
} 
flation, therefore acting as a demand shock. In this sense, our non-linear analysis offers solid support to the prediction by Leduc and Liu (2013) on the effects of uncertainty on unemployment.

Monthly data. Given the high number of parameters to estimate, our non-linear VAR model is very demanding on the data. We then augment the degrees of freedom of our empirical exercise by moving to monthly data. This move enables us to enjoy an additional benefit, i.e., our recursive identifying restriction becomes more plausible. Because of data availability, we consider CPI inflation (instead of GDP inflation) and work with a transition indicator constructed by using a twelve-terms moving average of the growth rate of industrial production. We then recalibrate our slope parameter $\gamma=1.8$ so to replicate the frequency of recessions in our sample conditional on this different transition indicator. As previously discussed, the implied transition probability of being in a recession tracks quite well the NBER recessions (see Figure A3). Figure A9 plots our responses conditional on monthly data. Again, the response of unemployment is estimated to be larger than the one predicted by a linear framework. 


\begin{tabular}{|c|c|c|c|c|c|}
\hline $\mathbf{N}$ & Series & Mnemonic & Tr. & Start & End \\
\hline 1 & Real Gross Domestic Product, 1 Decimal & GDPC 1 & 5 & 1947Q1 & $2012 \mathrm{Q} 3$ \\
\hline 2 & Real Gross National Product & GNPC 96 & 5 & 1947Q1 & $2012 \mathrm{Q} 3$ \\
\hline 3 & Real National Income & NICUR/GDPDEF & 5 & $1947 \mathrm{Q} 1$ & $2012 \mathrm{Q} 3$ \\
\hline 4 & Real Disposable Income & DPIC 96 & 5 & 1947Q1 & $2012 \mathrm{Q} 3$ \\
\hline 5 & Real Personal Income & RPI & 6 & 1959Q1 & $2012 \mathrm{Q} 3$ \\
\hline 6 & Nonfarm Business Sector: Output & OUTNFB & 5 & 1947Q1 & $2012 \mathrm{Q} 3$ \\
\hline 7 & Real Final Sales of Domestic Product, 1 Decimal & FINSLC 1 & 5 & $1947 \mathrm{Q} 1$ & $2012 \mathrm{Q} 3$ \\
\hline 8 & Real Private Fixed Investment, 1 Decimal & FPIC 1 & 5 & 1995Q1 & $2012 \mathrm{Q} 3$ \\
\hline 9 & Real Private Residential Fixed Investment, 1 Decimal & PRFIC 1 & 5 & $1995 \mathrm{Q} 1$ & $2012 \mathrm{Q} 3$ \\
\hline 10 & Real Private Nonresidential Fixed Investment, 1 Decimal & PNFIC1 & 5 & $1995 \mathrm{Q} 1$ & $2012 \mathrm{Q} 3$ \\
\hline 11 & Real Gross Private Domestic Investment, 1 Decimal & GPDIC 1 & 5 & 1947Q1 & $2012 \mathrm{Q} 3$ \\
\hline 12 & Real Personal Consumption Expenditure & PCECC 96 & 5 & $1947 \mathrm{Q} 1$ & $2012 \mathrm{Q} 3$ \\
\hline 13 & Real Personal Consumption Expenditure: Nondurable Goods & PCNDGC96 & 5 & 1995Q1 & $2012 \mathrm{Q} 3$ \\
\hline 14 & Real Personal Consumption Expenditure: Durable Goods & PCDGCC 96 & 5 & 1995Q1 & $2012 \mathrm{Q} 3$ \\
\hline 15 & Real Personal Consumption Expenditure: Services & PCESVC 96 & 5 & 1995Q1 & $2012 \mathrm{Q} 3$ \\
\hline 16 & Real Gross Private Saving & GPSAVE/GDPDEF & 5 & $1947 \mathrm{Q} 1$ & $2012 \mathrm{Q} 3$ \\
\hline 17 & Real Federal Consumption Expenditures, Gross Investment, 1 Decimal & FGCEC1 & 5 & 1995Q1 & $2012 \mathrm{Q} 3$ \\
\hline 18 & Federal Goverment: Current Expenditures, Real & FGEXPND/GDPDEF & 5 & $1947 \mathrm{Q} 1$ & $2012 \mathrm{Q} 3$ \\
\hline 19 & Federal Goverment: Current Receipts, Real & FGRECPT/GDPDEF & 5 & 1947Q1 & $2012 \mathrm{Q} 3$ \\
\hline 20 & Net Federal Government Saving & FGDEF & 2 & 1947Q1 & $2012 \mathrm{Q} 3$ \\
\hline 21 & Government Current Expenditures/GDP Deflator & GEXPND/GDPDEF & 5 & $1947 \mathrm{Q} 1$ & $2012 \mathrm{Q} 3$ \\
\hline 22 & Government Current Receipts/GDP Deflator & GRECPT/GDPDEF & 5 & $1947 \mathrm{Q} 1$ & $2012 \mathrm{Q} 3$ \\
\hline 23 & Government Real Expenditures minus Real Receipts & GDEF & 2 & $1947 \mathrm{Q} 1$ & $2012 \mathrm{Q} 3$ \\
\hline 24 & Real Government Consumption Expenditures, Gross Investment, 1 Decimal & GCEC1 & 5 & 1947Q1 & $2012 \mathrm{Q} 3$ \\
\hline 25 & Real Change in Private Inventories, 1 Decimal & CBIC 1 & 1 & 1947Q1 & $2012 \mathrm{Q} 3$ \\
\hline 26 & Real Exports of Goods and Services, 1 Decimal & EXPGSC1 & 5 & $1947 \mathrm{Q} 1$ & $2012 \mathrm{Q} 3$ \\
\hline 27 & Real Imports of Goods and Services, 1 Decimal & IMPGSC 1 & 5 & $1947 \mathrm{Q} 1$ & $2012 \mathrm{Q} 3$ \\
\hline 28 & Corporate Profits After Tax, Real & CP/GDPDEF & 5 & $1947 \mathrm{Q} 1$ & $2012 \mathrm{Q} 3$ \\
\hline 29 & Nonfinancial Corporate Business: Profits After Tax, Real & NFCPATAX/GDPDEF & 5 & 1947Q1 & $2012 \mathrm{Q} 3$ \\
\hline 30 & Corporate Net Cash Flow, Real & CNCF/GDPDEF & 5 & 1947Q1 & $2012 \mathrm{Q} 3$ \\
\hline 31 & Net Corporate Dividends, Real & DIVIDEND/GDPDEF & 5 & 1947Q1 & $2012 \mathrm{Q} 3$ \\
\hline 32 & Industrial Production Index & INDPRO & 5 & $1947 \mathrm{Q} 1$ & $2012 \mathrm{Q} 3$ \\
\hline 33 & Industrial Production: Business Equipment & IPBUSEQ & 5 & 1947Q1 & $2012 \mathrm{Q} 3$ \\
\hline 34 & Industrial Production: Consumer Goods & IPCONGD & 5 & 1947Q1 & $2012 \mathrm{Q} 3$ \\
\hline 35 & Industrial Production: Durable Consumer Goods & IPDCONGD & 5 & 1947Q1 & $2012 \mathrm{Q} 3$ \\
\hline 36 & Industrial Production: Final Products (Market Group) & IPFINAL & 5 & 1947Q1 & $2012 \mathrm{Q} 3$ \\
\hline 37 & Industrial Production: Materials & IPMAT & 5 & $1947 \mathrm{Q} 1$ & $2012 \mathrm{Q} 3$ \\
\hline 38 & Industrial Production: Nondurable Consumer Goods & IPNCONGD & 5 & 1947Q1 & $2012 \mathrm{Q} 3$ \\
\hline 39 & Capacity Utilization: Manufacturing & MCUMFN & 4 & $1972 \mathrm{Q} 1$ & $2012 \mathrm{Q} 3$ \\
\hline 40 & Industrial Production: Manufacturing & IPMAN & 5 & 1972Q1 & $2012 \mathrm{Q} 3$ \\
\hline 41 & Industrial Production: Durable Manufacturing & IPD M A N & 5 & $1972 \mathrm{Q} 1$ & $2012 \mathrm{Q} 3$ \\
\hline 42 & Industrial Production: Mining & IPMINE & 5 & $1972 \mathrm{Q} 1$ & $2012 \mathrm{Q} 3$ \\
\hline 43 & Industrial Production: Nondurable Manufacturing & IPNMAN & 5 & $1972 \mathrm{Q} 1$ & $2012 \mathrm{Q} 3$ \\
\hline 44 & Industrial Production: Durable Materials & IP D MAT & 5 & 1947Q1 & $2012 \mathrm{Q} 3$ \\
\hline 45 & Industrial Production: Electric and Gas Utilities & IPUTIL & 5 & $1972 \mathrm{Q} 1$ & $2012 \mathrm{Q} 3$ \\
\hline 46 & ISM Manufacturing: PMI Composite Index & NAPM & 1 & 1948Q1 & $2012 \mathrm{Q} 3$ \\
\hline 47 & ISM Manufacturing: Production Index & NAPMPI & 1 & $1948 \mathrm{Q} 1$ & $2012 \mathrm{Q} 3$ \\
\hline 48 & Average Weekly Hours of Production and Nonsupervisory Employees: Manuf. & AW HM AN & 1 & 1948Q1 & $2012 \mathrm{Q} 3$ \\
\hline 49 & Average Weekly Overtime Hours of Prod. and Nonsupervisory Employees: Manuf. & AWOTMAN & 2 & 1948Q1 & $2012 \mathrm{Q} 3$ \\
\hline 50 & Civilian Labor Force Participation Rate & CIVPART & 2 & 1948Q1 & $2012 \mathrm{Q} 3$ \\
\hline
\end{tabular}

Table A1. Time series employed for the computation of the factors. Description of the Table in two pages. 


\begin{tabular}{|c|c|c|c|c|c|}
\hline $\mathbf{N}$ & Series & Mnemonic & Tr. & Start & End \\
\hline 51 & Civilian Labor Force & CLF $160 \mathrm{~V}$ & 5 & 1948Q1 & $2012 \mathrm{Q} 3$ \\
\hline 52 & Civilian Employment & CE160V & 5 & 1948Q1 & $2012 \mathrm{Q} 3$ \\
\hline 53 & All Employees: Total Private Industries & USPRIV & 5 & 1947Q1 & $2012 \mathrm{Q} 3$ \\
\hline 54 & All Employees: Goods-Producing Industries & USGOOD & 5 & $1947 \mathrm{Q} 1$ & $2012 \mathrm{Q} 3$ \\
\hline 55 & All Employees: Service-Providing Industries & SRVPRD & 5 & $1947 \mathrm{Q} 1$ & $2012 \mathrm{Q} 3$ \\
\hline 56 & Unemployed & UNEMPLOY & 5 & 1948Q1 & $2012 \mathrm{Q} 3$ \\
\hline 57 & Average (Mean) Duration of Unemployment & UEMPMEAN & 2 & 1948Q1 & $2012 \mathrm{Q} 3$ \\
\hline 58 & Civilian Unemployment Rate & UNRATE & 2 & 1948Q1 & $2012 \mathrm{Q} 3$ \\
\hline 59 & Index of Help-Wanted Advertising in Newspapers & $\mathrm{A} 0 \mathrm{M} 046$ & 1 & $1959 \mathrm{Q} 1$ & $2012 \mathrm{Q} 3$ \\
\hline 60 & HOANBS/CNP $160 \mathrm{~V}$ & HOANBS/CNP $160 \mathrm{~V}$ & 4 & 1948Q1 & $2012 \mathrm{Q} 3$ \\
\hline 61 & Initial Claims & ICSA & 5 & $1967 \mathrm{Q} 3$ & $2012 \mathrm{Q} 3$ \\
\hline 62 & Housing Starts: Total: New Privately Owned Units Started & HOUST & 5 & $1959 \mathrm{Q} 1$ & $2012 \mathrm{Q} 3$ \\
\hline 63 & Housing Starts in Northeast Census Region & HOUSTNE & 5 & $1959 \mathrm{Q} 1$ & $2012 \mathrm{Q} 3$ \\
\hline 64 & Housing Starts in Midwest Census Region & HOUSTMW & 5 & $1959 \mathrm{Q} 1$ & $2012 \mathrm{Q} 3$ \\
\hline 65 & Housing Starts in South Census Region & HOUSTS & 5 & $1959 \mathrm{Q} 1$ & $2012 \mathrm{Q} 3$ \\
\hline 66 & Housing Starts in West Census Region & HOUSTW & 5 & 1959Q1 & $2012 \mathrm{Q} 3$ \\
\hline 67 & New Private Housing Units Authorized by Building Permits & PERMIT & 5 & $1960 \mathrm{Q} 1$ & $2012 \mathrm{Q} 3$ \\
\hline 68 & US Manufacturers New Orders for Non Defense Capital Goods & USNOIDN.D & 5 & $1959 \mathrm{Q} 2$ & $2012 \mathrm{Q} 3$ \\
\hline 69 & US New Orders of Consumer Goods and Materials & USCNORCGD & 5 & $1959 \mathrm{Q} 2$ & $2012 \mathrm{Q} 3$ \\
\hline 70 & US ISM Manufacturers Survey: New Orders Index SADJ & USNAPMNO & 1 & $1950 \mathrm{Q} 2$ & $2012 \mathrm{Q} 3$ \\
\hline 71 & Retail Sales: Total (Excluding Food Services) & RSXFS & 5 & $1992 \mathrm{Q} 1$ & $2012 \mathrm{Q} 3$ \\
\hline 72 & Value of Manufacturers' Total Inventories for All Manufacturing Industries & UMTMTI & 5 & 1992Q1 & $2012 \mathrm{Q} 3$ \\
\hline 73 & Value of Manufacturers' Total Inventories for Durable Goods & AMDMTI & 5 & 1992Q1 & $2012 \mathrm{Q} 3$ \\
\hline 74 & Value of Manufacturers' Total Inventories for Nondurable Goods Industries & AMNMTI & 5 & 1992Q1 & $2012 \mathrm{Q} 3$ \\
\hline 75 & ISM Manufacturing: Inventories Index & NAPMII & 1 & 1948Q1 & $2012 \mathrm{Q} 3$ \\
\hline 76 & ISM Manufacturing: New Orders Index & NAPMNOI & 1 & 1948Q1 & $2012 \mathrm{Q} 3$ \\
\hline 77 & Value of Manufacturers' New Orders for Cons. Goods: Cons. Dur. Goods Ind.s & ACDGNO & 5 & 1992Q1 & $2012 \mathrm{Q} 3$ \\
\hline 78 & Manuf.s' New Orders: Durable Goods & DGORDER & 5 & $1992 \mathrm{Q} 1$ & $2012 \mathrm{Q} 3$ \\
\hline 79 & Value of Manuf.s' New Orders for Dur. Goods Ind.: Transp. Equipment & ANAPNO & 5 & 1992Q1 & $2012 \mathrm{Q} 3$ \\
\hline 80 & Gross Domestic Product: Chain-type Price Index & GDPCTPI & 5 & 1947Q1 & $2012 \mathrm{Q} 3$ \\
\hline 81 & Gross National Product: Chain-type Price Index & GNPCTPI & 5 & $1947 \mathrm{Q} 1$ & $2012 \mathrm{Q} 3$ \\
\hline 82 & Gross Domestic Product: Implicit Price Deflator & GDPDEF & 5 & 1947Q1 & $2012 \mathrm{Q} 3$ \\
\hline 83 & Gross National Product: Implicit Price Deflator & GNPDEF & 5 & $1947 \mathrm{Q} 1$ & $2012 \mathrm{Q} 3$ \\
\hline 84 & Consumer Price Index for All Urban Consumers: All Items & CPIAUCSL & 6 & 1947Q1 & $2012 \mathrm{Q} 3$ \\
\hline 85 & Consumer Price Index for All Urban Consumers: All Items Less Food & CPIULFSL & 6 & $1947 \mathrm{Q} 1$ & $2012 \mathrm{Q} 3$ \\
\hline 86 & Consumer Price Index for All Urban Consumers: All Items Less Energy & CPILEGSL & 6 & $1957 \mathrm{Q} 1$ & $2012 \mathrm{Q} 3$ \\
\hline 87 & Consumer Price Index for All Urban Consumers: All Items Less Food \& Energy & CPILFESL & 6 & $1957 \mathrm{Q} 1$ & $2012 \mathrm{Q} 3$ \\
\hline 88 & Consumer Price Index for All Urban Consumers: Energy & CPIENGSL & 6 & $1947 \mathrm{Q} 1$ & $2012 \mathrm{Q} 3$ \\
\hline 89 & Consumer Price Index for All Urban Consumers: Food & CPIUFDSL & 6 & 1947Q1 & $2012 \mathrm{Q} 3$ \\
\hline 90 & Producer Price Index: Finished Goods: Capital Equipment & PPICPE & 6 & 1947Q1 & $2012 \mathrm{Q} 3$ \\
\hline 91 & Producer Price Index: Crude Materials for Further Processing & PPICRM & 6 & $1947 \mathrm{Q} 1$ & $2012 \mathrm{Q} 3$ \\
\hline 92 & Producer Price Index: Finished Consumer Goods & PPIFCG & 6 & 1947Q1 & $2012 \mathrm{Q} 3$ \\
\hline 93 & Producer Price Index: Finished Goods & PPIFGS & 6 & $1947 \mathrm{Q} 1$ & $2012 \mathrm{Q} 3$ \\
\hline 94 & Spot Oil Price: West Texas Intermediate & OILPRICE & 6 & 1947Q1 & $2012 \mathrm{Q} 3$ \\
\hline 95 & Nonfarm Business Sector: Hours of All Persons & HOANBS & 5 & $1947 \mathrm{Q} 1$ & $2012 \mathrm{Q} 3$ \\
\hline 96 & Nonfarm Business Secotr: Output Per Hour of All Persons & OPHNFB & 5 & $1947 \mathrm{Q} 1$ & $2012 \mathrm{Q} 3$ \\
\hline 97 & Nonfarm Business Sector: Unit Nonlabor Payments & UNLPNBS & 5 & $1947 \mathrm{Q} 1$ & $2012 \mathrm{Q} 3$ \\
\hline 98 & Nonfarm Business Sector: Unit Labor Cost & ULCNFB & 5 & 1947Q1 & $2012 \mathrm{Q} 3$ \\
\hline 99 & Compensation of Employees: Wages and Salary Accruals, Real & WASCUR/CPI & 5 & 1947Q1 & $2012 \mathrm{Q} 3$ \\
\hline 100 & Nonfarm Business Sector: Compensation Per Hour & COMPNFB & 5 & 1947Q1 & $2012 \mathrm{Q} 3$ \\
\hline
\end{tabular}

Table A1 (continued). Time series employed for the computation of the factors. Description of the Table in the following page. 


\begin{tabular}{|c|c|c|c|c|c|}
\hline $\mathbf{N}$ & Series & Mnemonic & Tr. & Start & End \\
\hline 101 & Nonfarm Business Sector: Real Compensation Per Hour & COMPRNFB & 5 & $1947 \mathrm{Q} 1$ & $2012 \mathrm{Q} 3$ \\
\hline 102 & Growth in utilization-adjusted TFP & dtfp_util & 1 & $1947 \mathrm{Q} 2$ & $2012 \mathrm{Q} 3$ \\
\hline 103 & Growth in business sector TFP & dtfp & 1 & $1947 \mathrm{Q} 2$ & $2012 \mathrm{Q} 3$ \\
\hline 104 & Utilization in producing investment & $\mathrm{du}_{-}$invest & 1 & $1947 \mathrm{Q} 2$ & $2012 \mathrm{Q} 3$ \\
\hline 105 & Utilization in producing non-investment business output & du_consumption & 1 & $1947 \mathrm{Q} 2$ & $2012 \mathrm{Q} 3$ \\
\hline 106 & Utilization-adjusted TFP in producing equipment and consumer durables & dtfp_I_util & 1 & $1947 \mathrm{Q} 2$ & $2012 \mathrm{Q} 3$ \\
\hline 107 & Utilization-adjusted TFP in producing non-equipment output & dtfp_C_util & 1 & $1947 \mathrm{Q} 2$ & $2012 \mathrm{Q} 3$ \\
\hline 108 & Effective Federal Funds Rate & FEDFUNDS & 2 & $1954 \mathrm{Q} 3$ & $2012 \mathrm{Q} 3$ \\
\hline 109 & 3-Month Treasury Bill: Secondary Market Rate & TB3MS & 2 & 1947Q1 & $2012 \mathrm{Q} 3$ \\
\hline 110 & 1-Year Treasury Constant Maturity Rate & GS1 & 2 & $1953 \mathrm{Q} 2$ & $2012 \mathrm{Q} 3$ \\
\hline 111 & 10-Year Treasury Constant Maturity Rate & GS10 & 2 & $1953 \mathrm{Q} 2$ & $2012 \mathrm{Q} 3$ \\
\hline 112 & Moody's Seasoned Aaa Corporate Bond Yield & AAA & 2 & 1947Q1 & $2012 \mathrm{Q} 3$ \\
\hline 113 & Moody's Seasoned Baa Corporate Bond Yield & BAA & 2 & $1947 \mathrm{Q} 1$ & $2012 \mathrm{Q} 3$ \\
\hline 114 & Bank Prime Loan Rate & MPRIME & 2 & 1949Q1 & $2012 \mathrm{Q} 3$ \\
\hline 115 & GS10-FEDFUNDS Spread & GS10-FEDFUNDS & 1 & $1954 \mathrm{Q} 3$ & $2012 \mathrm{Q} 3$ \\
\hline 116 & GS1-FEDFUNDS Spread & GS1-FEDFUNDS & 1 & $1954 \mathrm{Q} 3$ & $2012 \mathrm{Q} 3$ \\
\hline 117 & BAA-FEDFUNDS Spread & BAA-FEDFUNDS & 1 & $1954 \mathrm{Q} 3$ & $2012 \mathrm{Q} 3$ \\
\hline 118 & Non-Borrowed Reserves of Depository Institutions & BOGNONBR & 5 & $1959 \mathrm{Q} 1$ & $2012 \mathrm{Q} 3$ \\
\hline 119 & Board of Gov. Total Reserves, Adjusted for Changes in Reserve Requirements & TRARR & 5 & $1959 \mathrm{Q} 1$ & $2012 \mathrm{Q} 3$ \\
\hline 120 & Board of Gov. Monetary Base, Adjusted for Changes in Reserve Requirements & BOGAMBSL & 5 & 1959Q1 & $2012 \mathrm{Q} 3$ \\
\hline 121 & M1 Money Stock & M1SL & 5 & $1959 \mathrm{Q} 1$ & $2012 \mathrm{Q} 3$ \\
\hline 122 & M2 Less Small Time Deposits & M 2MSL & 5 & $1959 \mathrm{Q} 1$ & $2012 \mathrm{Q} 3$ \\
\hline 123 & M2 Money Stock & $\mathrm{M} 2 \mathrm{SL}$ & 5 & 1959Q1 & $2012 \mathrm{Q} 3$ \\
\hline 124 & Commercial and Industrial Loans at All Commercial Banks & BUSLOANS & 5 & 1947Q1 & $2012 \mathrm{Q} 3$ \\
\hline 125 & Consumer Loans at All Commercial Banks & CONSUMER & 5 & 1947Q1 & $2012 \mathrm{Q} 3$ \\
\hline 126 & Bank Credit at All Commercial Banks & LOANINV & 5 & $1947 \mathrm{Q} 1$ & $2012 \mathrm{Q} 3$ \\
\hline 127 & Real Estate Loans at All Commercial Banks & REALLN & 5 & 1947Q1 & $2012 \mathrm{Q} 3$ \\
\hline 128 & Total Consumer Credit $\mathrm{O}$ wned and Securitized, Outstanding & TOTALSL & 5 & 1947Q1 & $2012 \mathrm{Q} 3$ \\
\hline 129 & St. Louis Adjusted Monetary Base & AMBSL (CHNG) & 5 & 1947Q1 & $2012 \mathrm{Q} 3$ \\
\hline 130 & US Dow Jones Industrials Share Price Index (EP) & USSHRPRCF & 5 & $1950 \mathrm{Q} 2$ & $2012 \mathrm{Q} 3$ \\
\hline 131 & US Standard \& Poor's Index of 500 Common Stocks & US500STK & 5 & $1950 \mathrm{Q} 2$ & $2012 \mathrm{Q} 3$ \\
\hline 132 & US Share Price Index NADJ & USI62 $\ldots \mathrm{F}$ & 5 & $1957 \mathrm{Q} 2$ & $2012 \mathrm{Q} 3$ \\
\hline 133 & Dow Jones/GDP Deflator & DOW Jones/GDPDEF & 5 & $1950 \mathrm{Q} 2$ & $2012 \mathrm{Q} 3$ \\
\hline 134 & S\&P/GDP Deflator & S\&P/GDPDEF & 5 & $1950 \mathrm{Q} 2$ & $2012 \mathrm{Q} 3$ \\
\hline 135 & Trade Weighted U.S. Dollar Index: Major Currencies & TWEXMMTH & 2 & $1973 \mathrm{Q} 1$ & $2012 \mathrm{Q} 3$ \\
\hline 136 & Euro/U.S. Foreign Exchange Rate & EXUSEU $(-1)$ & 5 & 1999Q1 & $2012 \mathrm{Q} 3$ \\
\hline 137 & Germany/U.S. Foreign Exchange Rate & EXGEUS & 5 & 1971Q1 & $2001 \mathrm{Q} 4$ \\
\hline 138 & Switzerland/U.S. Foreign Exchange Rate & EXSZUS & 5 & 1971Q1 & $2012 \mathrm{Q} 3$ \\
\hline 139 & Japan/U.S. Foreign Exchange Rate & EXJPUS & 5 & 1971Q1 & $2012 \mathrm{Q} 3$ \\
\hline 140 & U.K./U.S. Foreign Exchange Rate & EXUSUK(-1) & 5 & 1971Q1 & $2012 \mathrm{Q} 3$ \\
\hline 141 & Canada/U.S. Foreign Exchange Rate & EXCAUS & 5 & 1971Q1 & $2012 \mathrm{Q} 3$ \\
\hline 142 & US The Conference Board Leading Economic Indicators Index SADJ & USCYLEADQ & 5 & $1959 \mathrm{Q} 1$ & $2012 \mathrm{Q} 3$ \\
\hline 143 & US Economic Cycle Research Institute Weekly Leading Index & USECRIWLH & 5 & $1950 \mathrm{Q} 2$ & $2012 \mathrm{Q} 3$ \\
\hline 144 & University of Michigan Consumer Sentiment: Personal Finances, Current & USUMPFNCH & 2 & 1978Q1 & $2012 \mathrm{Q} 3$ \\
\hline 145 & University of Michigan Consumer Sentiment: Personal Finances, Expected & USUMPFNEH & 2 & 1978Q1 & $2012 \mathrm{Q} 3$ \\
\hline 146 & University of Michigan Consumer Sentiment: Economic Outlook, 12 Months & USUMECO1H & 2 & 1978Q1 & $2012 \mathrm{Q} 3$ \\
\hline 147 & University of Michigan Consumer Sentiment: Economic Outlook, 5 Years & USUMECO5H & 2 & $1978 \mathrm{Q} 1$ & $2012 \mathrm{Q} 3$ \\
\hline 148 & University of Michigan Consumer Sentiment: Buying Conditions, Durables & USUMBUYDH & 2 & $1978 \mathrm{Q} 1$ & $2012 \mathrm{Q} 3$ \\
\hline 149 & University of Michigan Consumer Sentiment Index & USUMCONSH & 2 & 1991Q1 & $2012 \mathrm{Q} 3$ \\
\hline 150 & University of Michigan Consumer Sentiment - Current Conditions & USUMCNSUR & 2 & 1991Q1 & $2012 \mathrm{Q} 3$ \\
\hline
\end{tabular}

Table A1 (continued). Time series employed for the computation of the factors. Classification of the series: 1-31: "NIPA"; 32-47: "Industrial Production"; 48-61: "Employment and Unemployment"; 62-67: "Housing Starts"; 68-79: "Inventories", "Orders and Sales"; 80-94: "Prices"; 95-107: "Earnings and Productivity"; 108-117: "Interest Rates"; 118-129: "Money and Credit"; 130134: "Stock Prices"; 135-141: "Exchange Rates"; 142-150: "Others". The column labeled "Tr." indicates the transformation applied to the series $(1=$ level, $2=$ first difference, $3=\operatorname{logarithm}, 4=$ second difference, $5=$ first difference of logarithm, $6=$ second difference of logarithm). Data source: Federal Reserve Bank of St. Louis' website. 
U nce rta inty

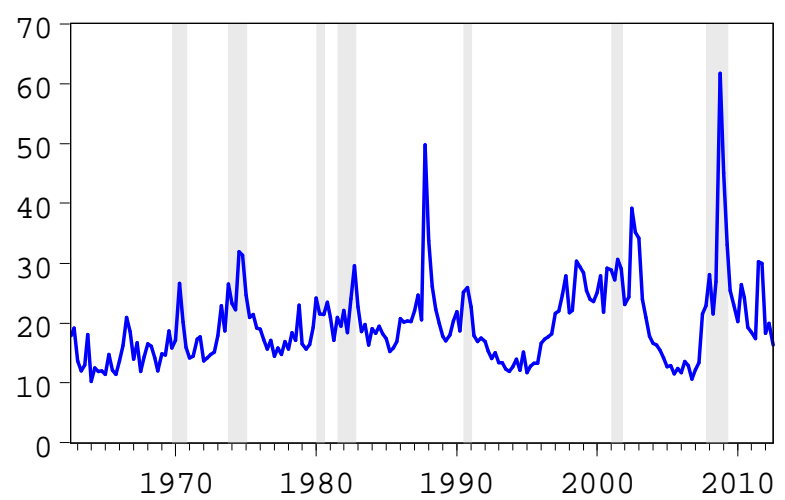

U nem ploym ent

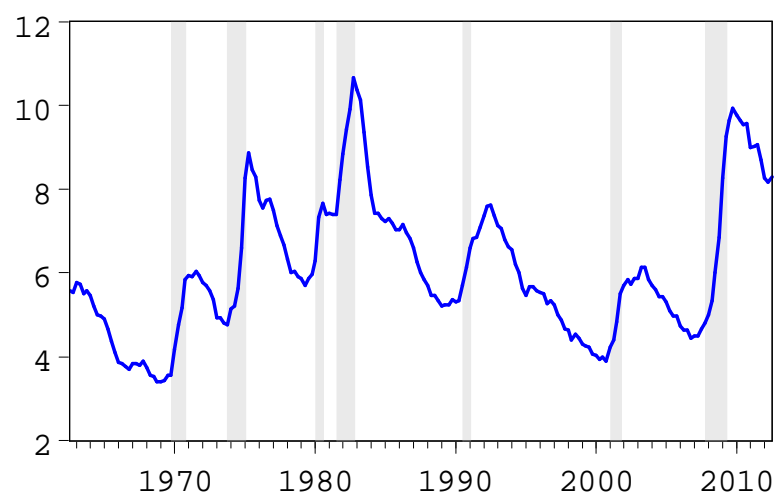

In flation

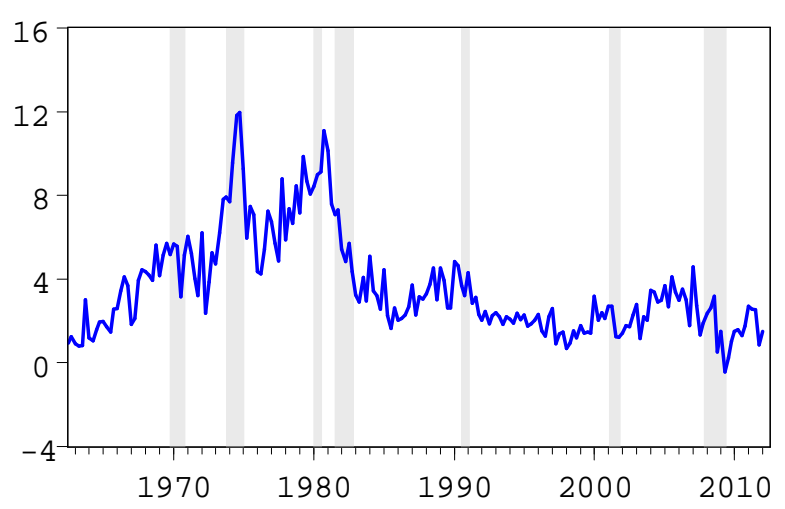

P olicy rate

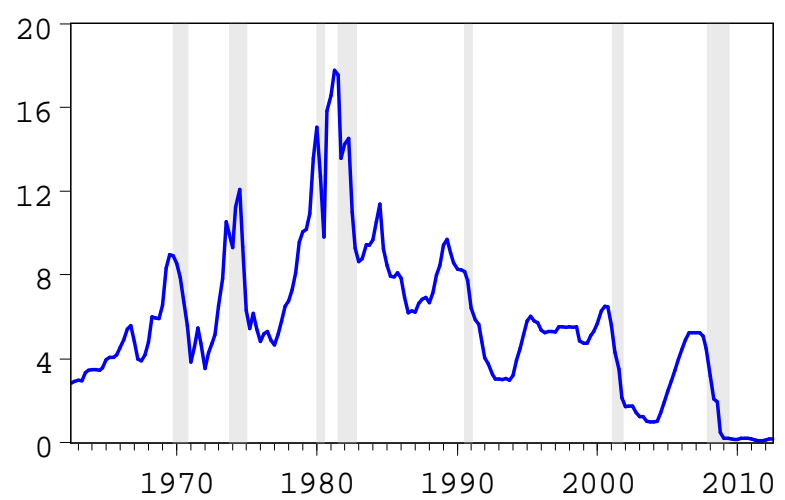

Figure A1 - Macroeconomic variables. Sample: 1962Q3-2012Q3. Uncertainty measured with the VIX as in Bloom (2009). Inflation measured as the annualized quarter-on-quarter growth rate of the implicit GDP deflator. Unemployment is the Civilian Unemployment rate. Policy rate is the Federal Funds Rate. 


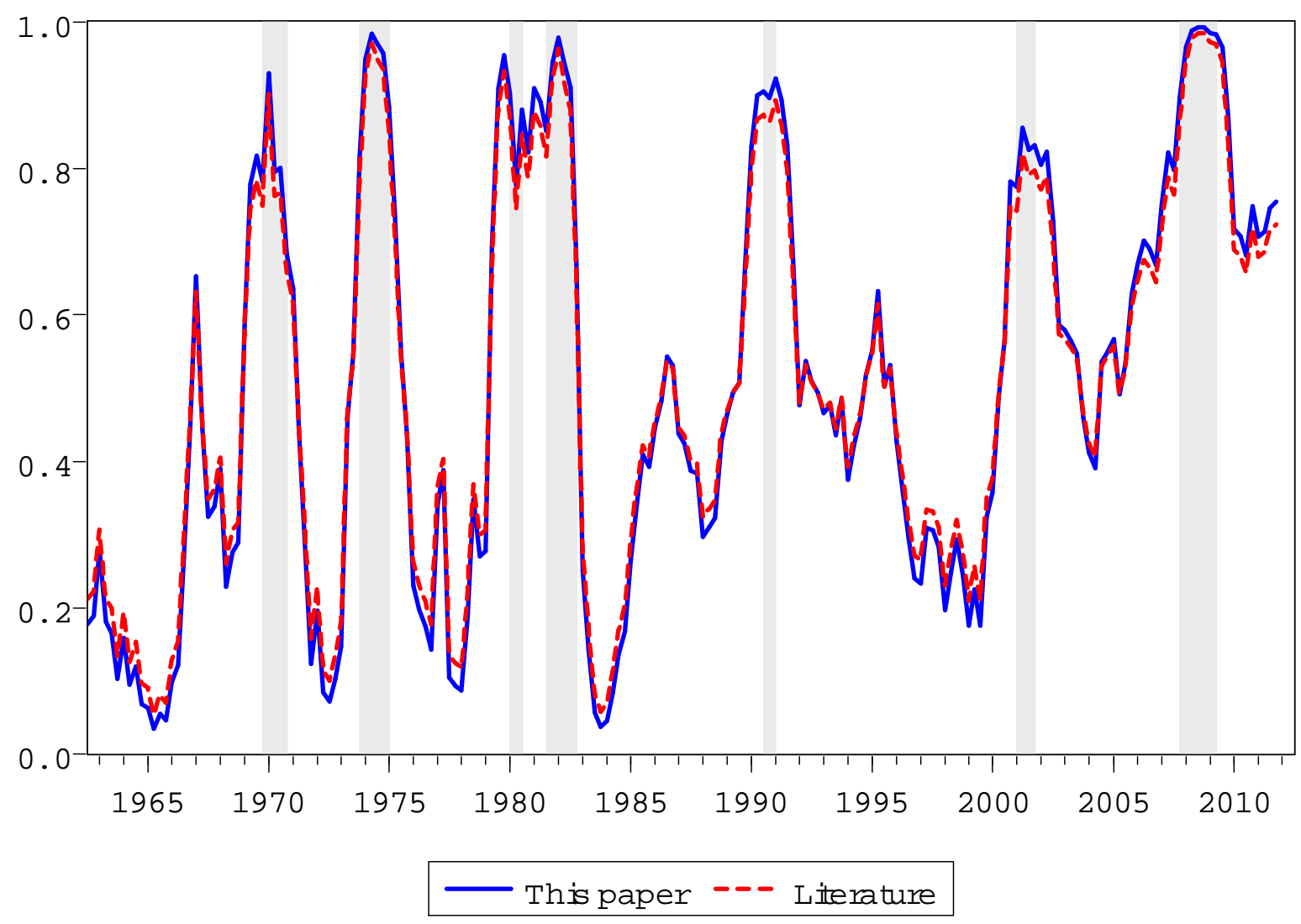

Figure A2 - Probability of being in a recessionary phase. Blue solid line: Transition function $\mathrm{F}(\mathrm{z})$ as in this paper, which is conditional on a slope parameter $=1.75$. Red dotted line: Transition function $\mathrm{F}(\mathrm{z})$ as in Auerbach and Gorodnichenko (2012), Bachmann and Sims (2012), and Berger and Vavra (2014), which is conditional on a slope parameter $=1.5$. Shaded columns: NBER recessions. 


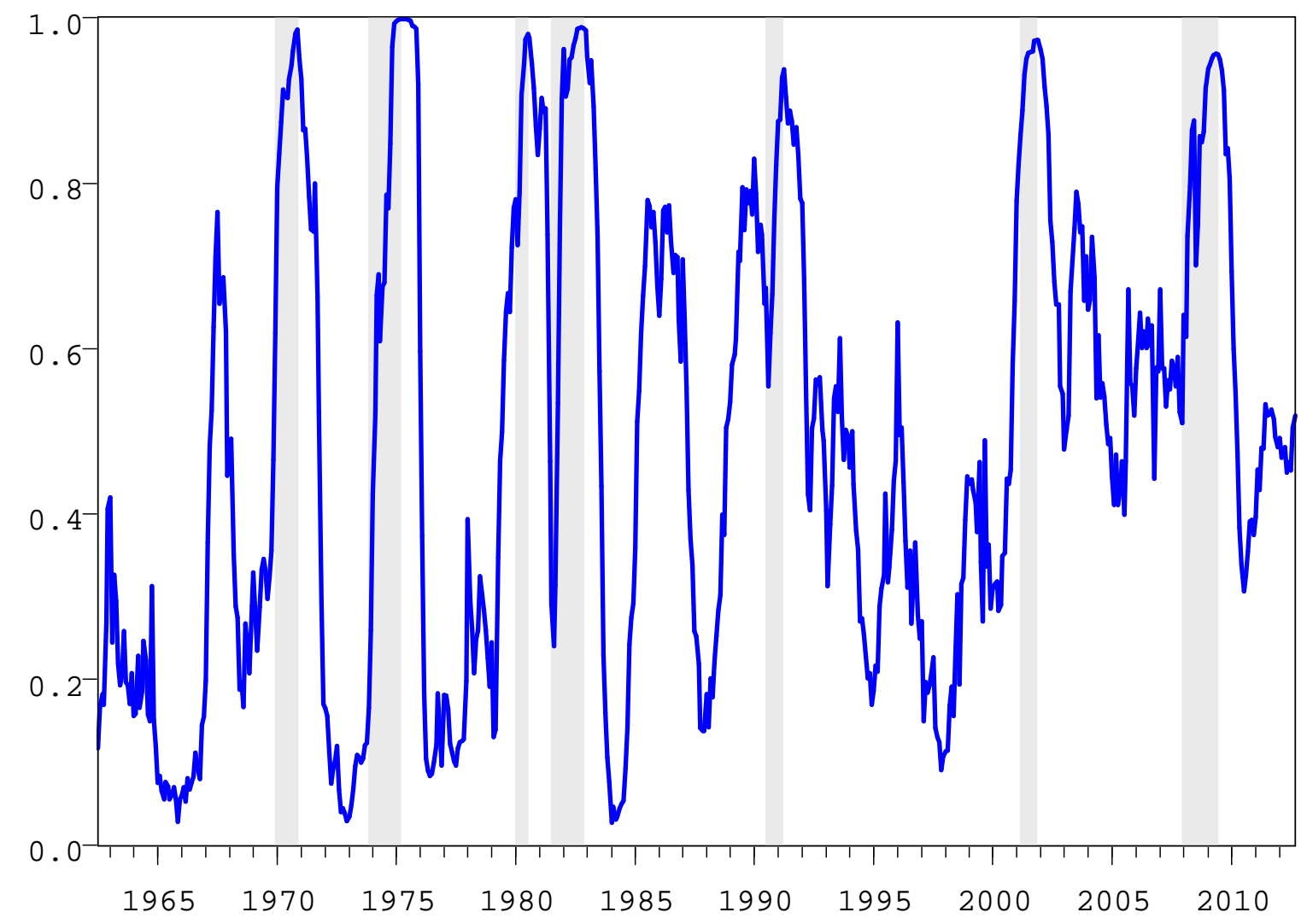

Figure A3 - Probability of being in a recessionary phase/monthly data. Blue solid line: Transition function $\mathrm{F}(\mathrm{z})$. Shaded columns: NBER recessions. 

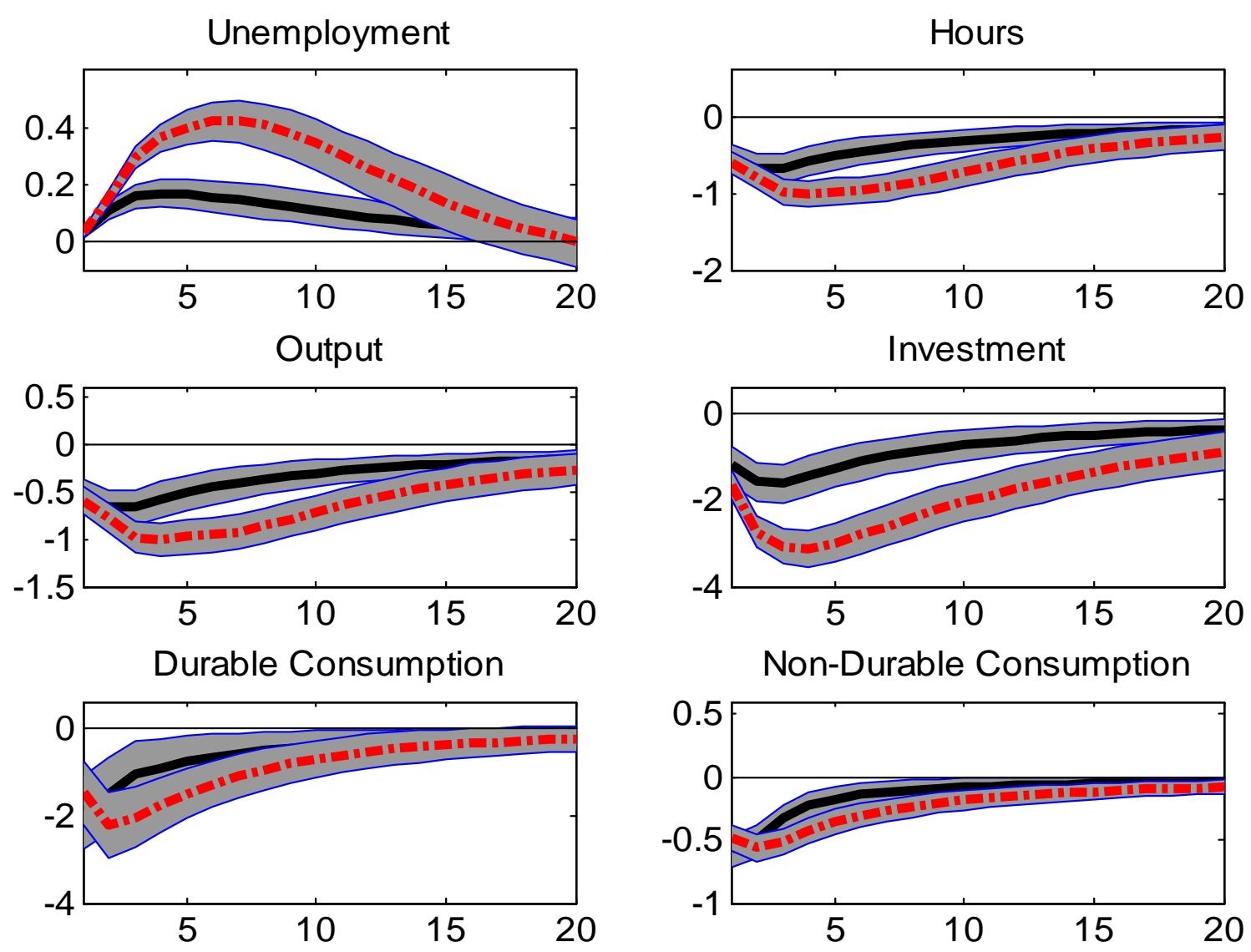

Figure A4 - Macroeconomic effects of uncertainty in recessions: Real activity indicators. Effects of a one standard deviation shock to VIX. Sample: 1962Q32012Q3. Solid black lines: Responses predicted by a linear VAR. Dash-dotted red lines: Reactions under recessions computed with our non-linear framework. VARs with four variables (uncertainty, inflation, indicator of real activity, policy rate). Gray areas: $68 \%$ bootstrapped confidence bands. Indicators of real activity considered in cumulated growth rates (average values). Shocks identified with a Cholesky-decomposition of the variance-covariance matrix of the reduced-form residuals. 

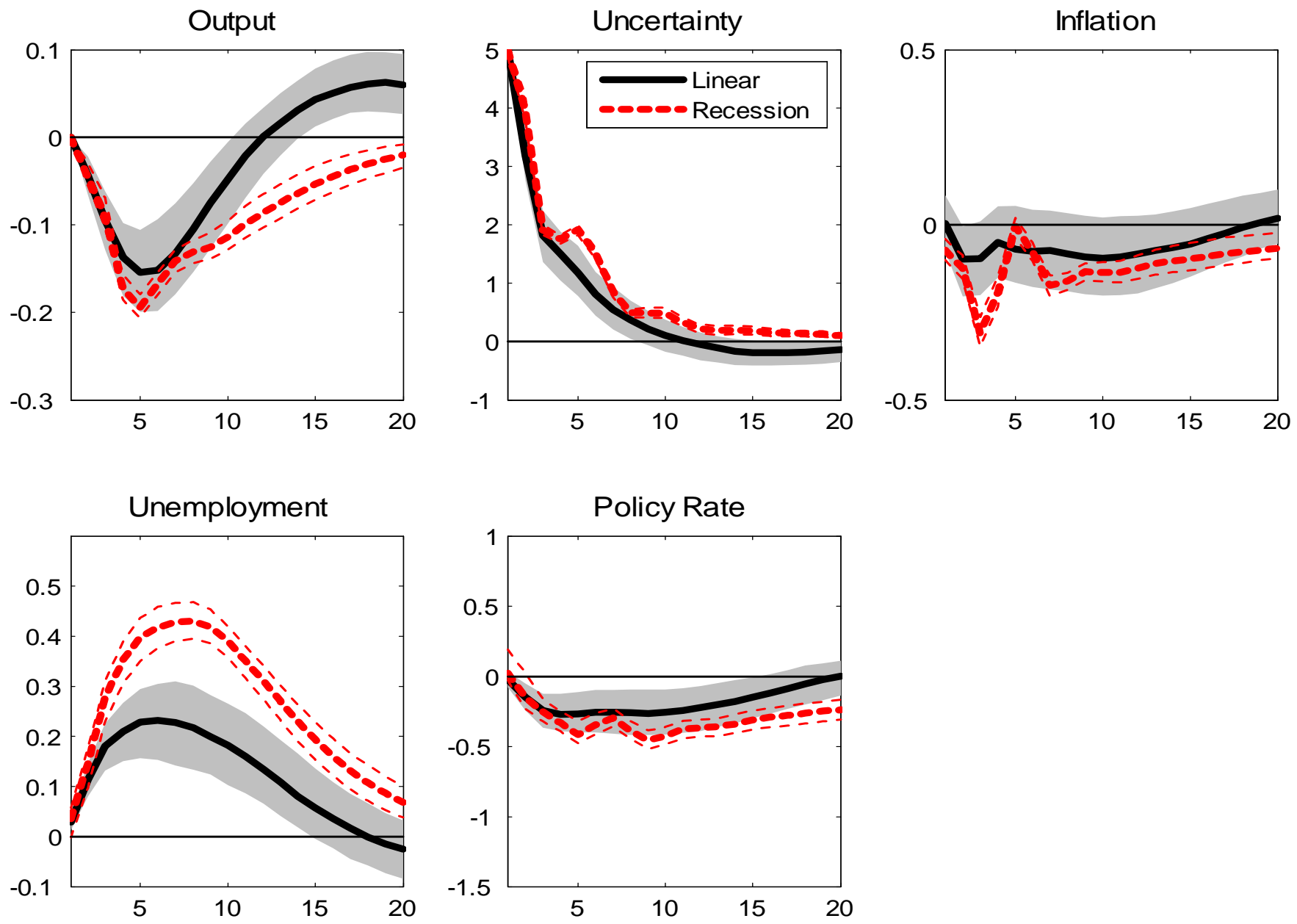

Figure A5 - Generalized Impulse Response Functions to an uncertainty shock. Effects of a one standard deviation shock to VIX. Sample: 1962Q3-2012Q3. Solid black lines: Responses predicted by a linear VAR. Dash-dotted red lines: Reactions under recessions computed with our non-linear framework. Baseline VAR with four variables (uncertainty, inflation, unemployment, policy rate). Gray areas: 68\% bootstrapped confidence bands. Shocks identified with a Cholesky-decomposition of the variance-covariance matrix of the reduced-form residuals. Generalized Impulse Responses computed by accounting for the feedback going from the (responses of the) variables modeled in the vector to the probability of staying in a recessionary-phase as in Koop, Pesaran, and Potter (1996). Vector to compute the GIRFs estimated by considering the transition indicator $z$ (standardized backward-looking moving average (seven terms) of the real GDP growth rate) as first variable (labeled as "output" in the Figure) in the vector. 

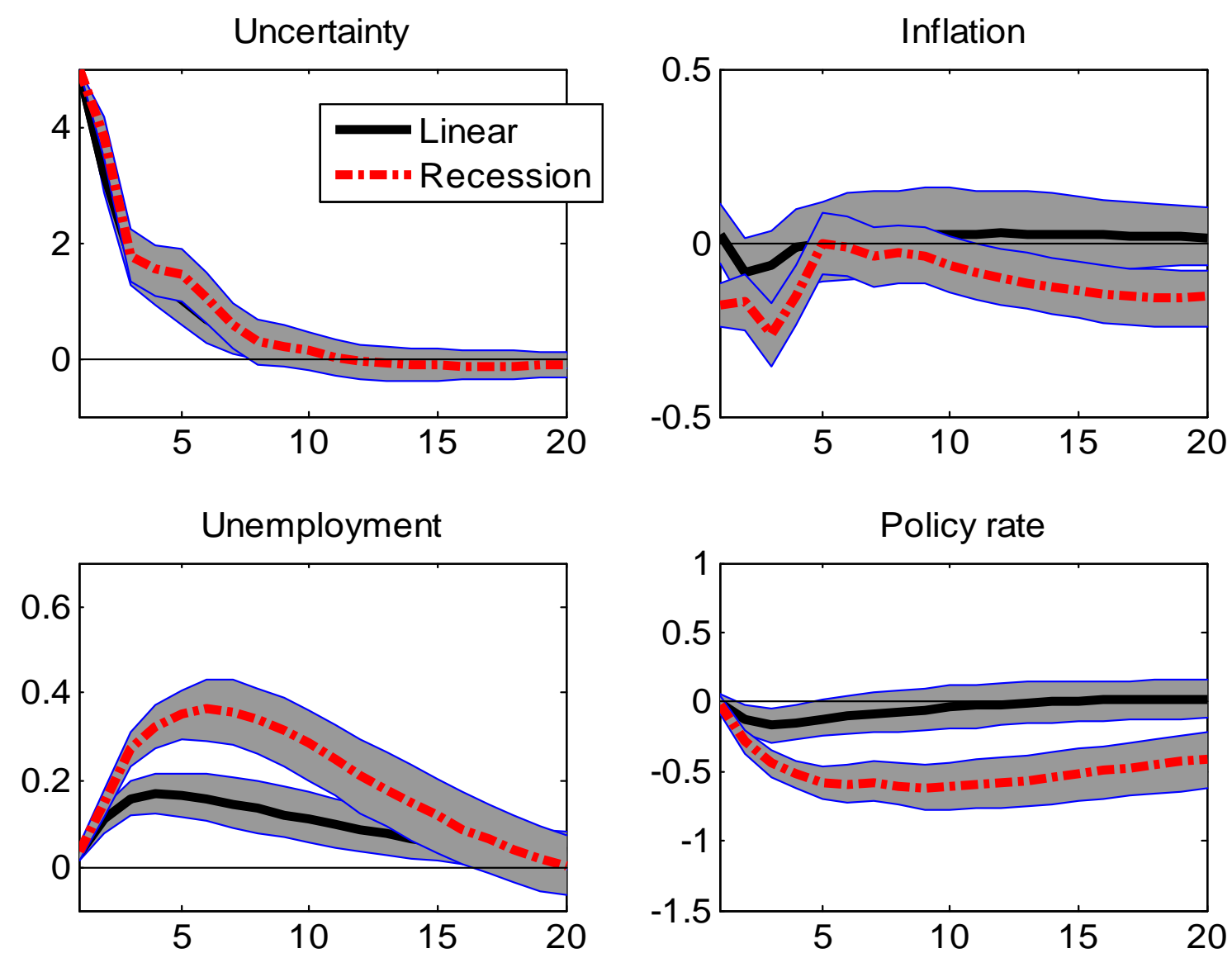

Figure A6 - Macroeconomic effects of uncertainty in recessions: High gamma. Slope parameter gamma set to 2.4 , a value implying a frequency of recessions in the sample equal to $10 \%$ (conditional on our transition indicator). Effects of a one standard deviation shock to VIX. Sample: 1962Q3-2012Q3. Solid black lines: Responses predicted by a linear VAR. Dash-dotted red lines: Reactions under recessions computed with our non-linear framework. Baseline VAR with four variables (uncertainty, inflation, unemployment, policy rate). Gray areas: 68\% bootstrapped confidence bands. Shocks identified with a Cholesky-decomposition of the variance-covariance matrix of the reduced-form residuals. 

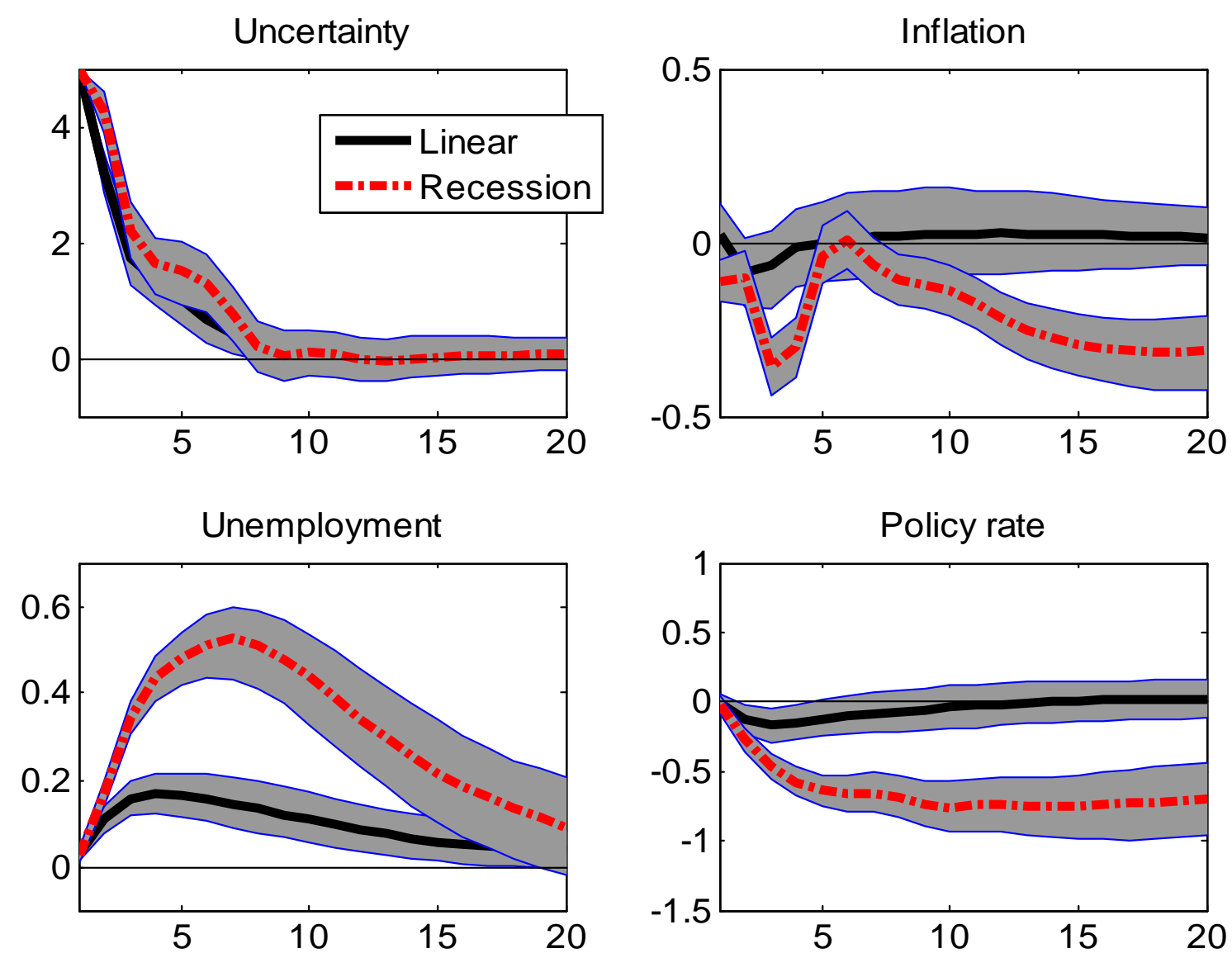

Figure A7 - Macroeconomic effects of uncertainty in recessions: Low gamma. Slope parameter gamma set to 1.2, a value implying a frequency of recessions in the sample equal to $25 \%$ (conditional on our transition indicator). Effects of a one standard deviation shock to VIX. Sample: 1962Q3-2012Q3. Solid black lines: Responses predicted by a linear VAR. Dash-dotted red lines: Reactions under recessions computed with our non-linear framework. Baseline VAR with four variables (uncertainty, inflation, unemployment, policy rate). Gray areas: 90\% confidence sets. Shocks identified with a Cholesky-decomposition of the variance-covariance matrix of the reduced-form residuals. 

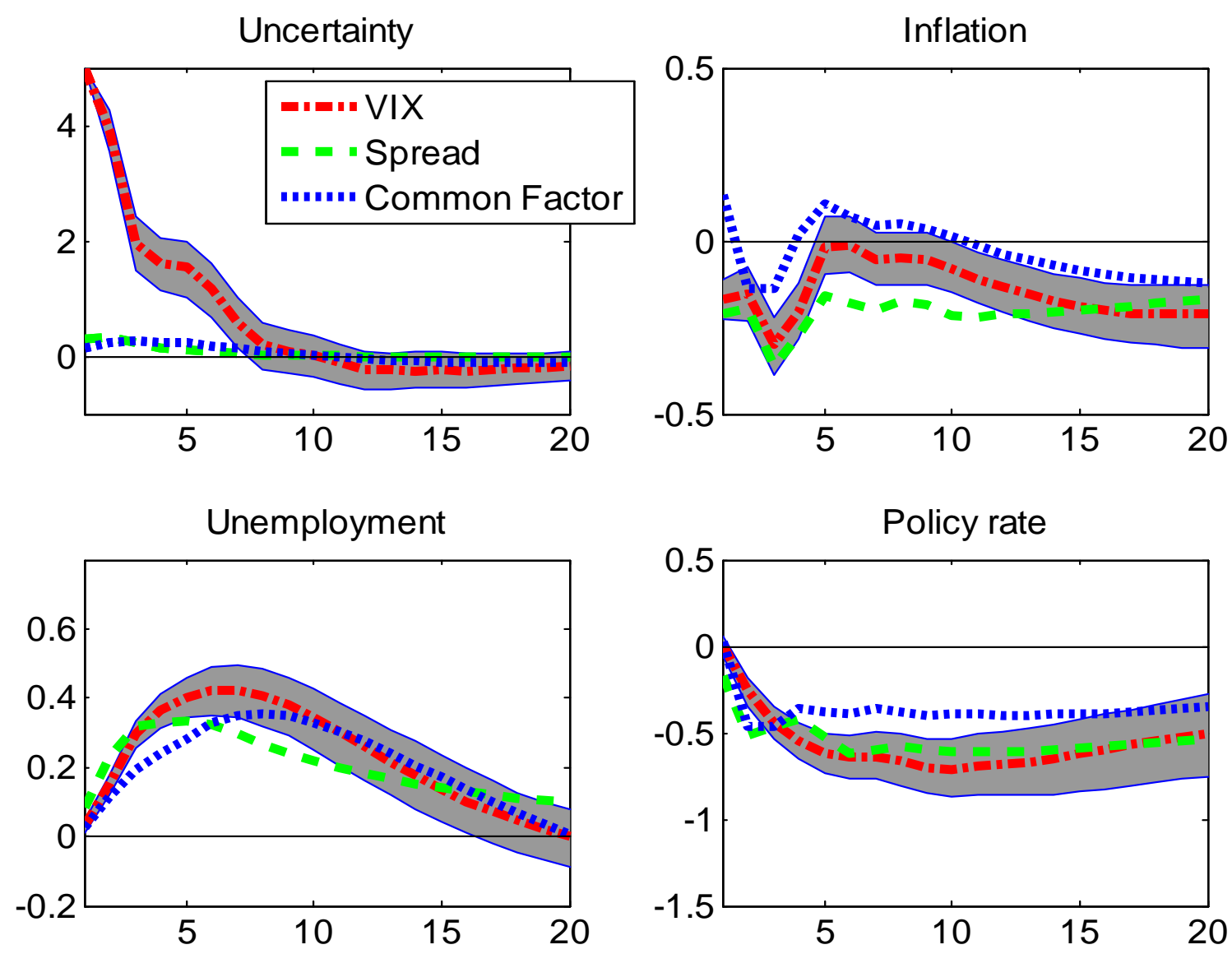

Figure A8 - Impact of uncertainty measures: Comparison. Effects of a one standard deviation shock to each uncertainty indicator. Note: VIX and (Corporate Bond) Spread, sample: 1962Q3-2012Q3. Common Factor: Common factor of the one year-ahead forecast error variance of a large number of time-series computed by Jurado, Ludvigson, and $\mathrm{Ng}$ (2013). Quarterly realizations computed as within-quarter averages of monthly estimates. Gray areas: $68 \%$ bootstrapped confidence bands. Note: Sample of the Forec. Error Common Factor analysis: 1962Q3-2011Q4 (due to data availability). 

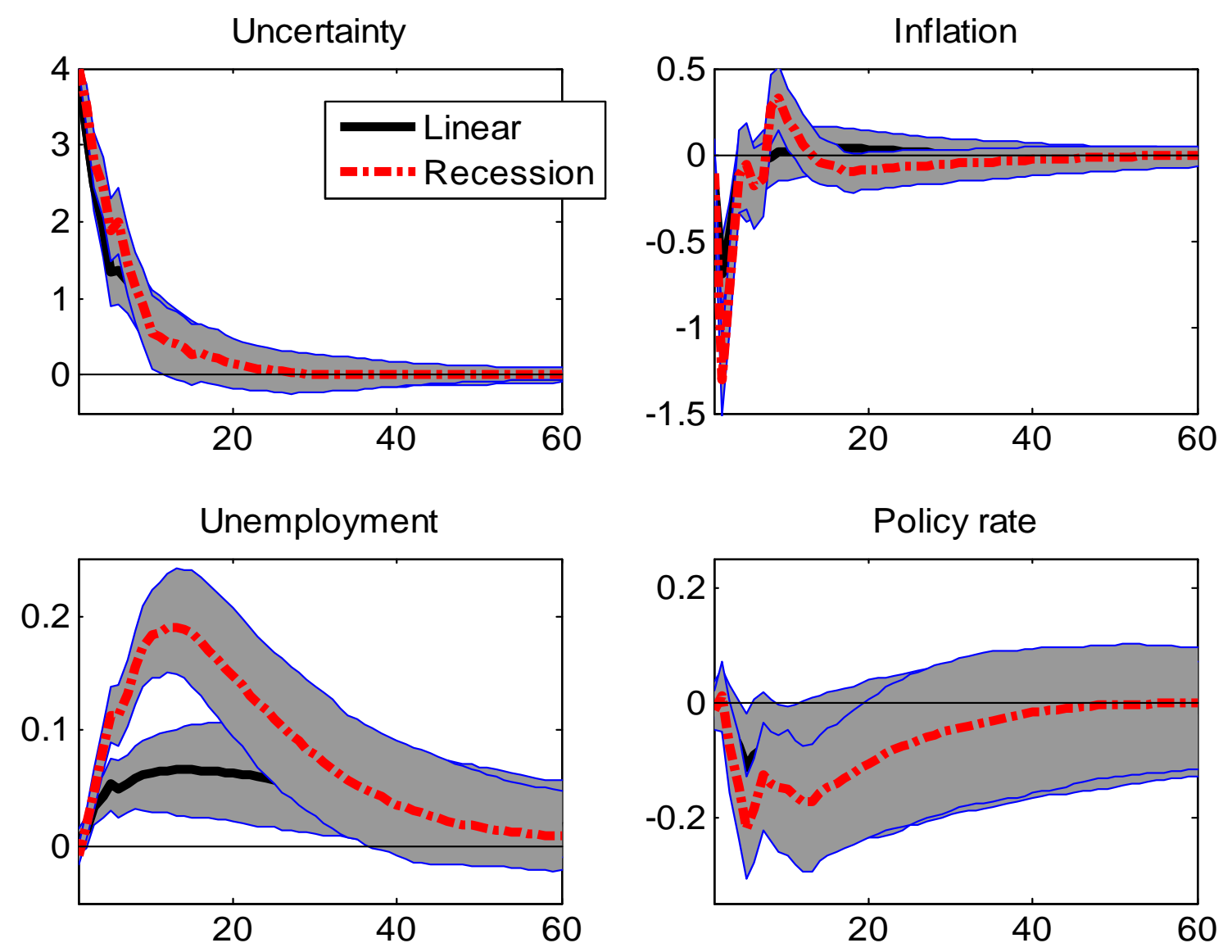

Figure A9 - Macroeconomic effects of uncertainty in recessions: Monthly data. Effects of a one standard deviation shock to VIX. Sample: 1962M7-2012M9. Solid black lines: Responses predicted by a linear VAR. Dash-dotted red lines: Reactions under recessions computed with our non-linear framework. Baseline VAR with four variables (uncertainty, CPI inflation, unemployment, policy rate). Gray areas: 68\% bootstrapped confidence bands. Shocks identified with a Cholesky-decomposition of the variance-covariance matrix of the reduced-form residuals. 


\section{References}

Auerbach, A., and Y. Gorodnichenko (2012): "Measuring the Output Responses to Fiscal Policy," American Economic Journal: Economic Policy, 4(2), 1-27.

Bachmann, R., S. Elstner, and E. Sims (2013): "Uncertainty and Economic Activity: Evidence from Business Survey Data," American Economic Journal: Macroeconomics, 5(2), 217-249.

Basu, S., J. Fernald, And M. Kimball (2006): "Are Technology Improvements Contractionary?," American Economic Review, 96, 1418-1448.

Berger, D., And J. Vavra (2014): "Measuring How Fiscal Shocks Affect Durable Spending in Recessions and Expansions," American Economic Review Papers and Proceedings, 104(5), 112-115.

Bloom, N. (2009): "The Impact of Uncertainty Shocks," Econometrica, 77(3), 623685.

Canova, F. (2007): Methods for Applied Macroeconomic Research, Princeton University Press, Princeton, New Jersey.

Chernozhukov, V., And H. Hong (2003): "An MCMC Approach to Classical Estimation," Journal of Econometrics, 115(2), 293-346.

Forni, M., And L. Gambetti (2014): "Sufficient information in structural VARs," Journal of Monetary Economics, 66, 124-136.

Hamilton, J. D. (1994): Time Series Analysis, Princeton University Press, Princeton, New Jersey.

Hansen, B. E. (1999): "Testing for Linearity," Journal of Economic Surveys, 13(5), $551-576$.

Jurado, K., S. C. Ludvigson, And S. NG (2015): "Measuring Uncertainty," American Economic Review, 105(3), 1177-1216.

Leduc, S., And Z. Liu (2013): "Uncertainty Shocks are Aggregate Demand Shocks," Federal Reserve Bank of San Francisco, Working Paper 2012-10.

Luukkonen, R., P. Saikkonen, and T. TerÄsvirta (1988): "Testing linearity against smooth transition autoregressive models," Biometrika, 75, 491-499.

Stock, J. H., And M. W. WAtson (2002): "Macroeconomic Forecasting Using Diffusion Indexes," Journal of Business and Economic Statistics, 20, 147-162.

(2012): "Disentangling the Channels of the 2007-2009 Recession," Brookings Papers on Economic Activity, pp. 81-135.

Tsay, R. (1986): "Nonlinearity tests for time series," Biometrika, 73, 461-466. 